\title{
EVALUATING THE EMPLOYMENT IMPACT OF A MANDATORY JOB SEARCH PROGRAM
}

\section{Richard Blundell}

University College London and Institute for Fiscal Studies

Monica Costa Dias

Institute for Fiscal Studies
Costas Meghir

University College London and Institute for Fiscal Studies

John Van Reenen

London School of Economics and Center for Economic Performance

\begin{abstract}
This paper exploits area-based piloting and age-related eligibility rules to identify treatment effects of a labor market program-the New Deal for Young People in the U.K. A central focus is on substitution/displacement effects and on equilibrium wage effects. The program includes extensive job assistance and wage subsidies to employers. We find that the impact of the program significantly raised transitions to employment by about 5 percentage points. The impact is robust to a wide variety of nonexperimental estimators. However, we present some evidence that this effect may not be as large in the longer run. (JEL: J18, J23, J38)
\end{abstract}

\section{Introduction}

The literature on the evaluation of labor market programs is voluminous, growing and somewhat sobering. Although most of evidence suggests these interventions have limited effects, especially when targeted at the young lowskilled adults, there is still scope for some variation depending on the type of treatment and the characteristics of the treatment group. This paper concerns the evaluation of a targeted active labor market program, "New Deal for the Young Unemployed," designed to move young unemployed individuals in the U.K. into work and away from welfare. This is a major program that has affected several

Acknowledgments: We thank David Card, Richard Freeman, James Heckman, Hide Ichimura, Richard Layard, Rebecca Riley, Garry Young, the coeditor, referee, and participants in seminars at Institute for Fiscal Studies, CEMFI, LSE, DfES, and St. Andrews. We are grateful to the Leverhulme foundation for funding this project. This research is also part of the program of research at the ESRC Centre for the Microeconomic Analysis of Public Policy at Institute for Fiscal Studies. The DfES kindly provided access to NDED and the ESRC Data Archive to the JUVOS data. The second author acknowledges the financial support from Sub-Programa Ciência e Tecnologia do Segundo Quadro Comunitário de Apoio, grant number PRAXIS XXI/BD/11413/97. The usual disclaimer applies.

E-mail addresses: Blundell: r.Blundell@ucl.ac.uk; Costa Dias: monica-d@ifs.org.uk;

Meghir: c.meghir@ucl.ac.uk; Van Reenen: j.vanreenen@1se.ac.uk 
million young people. It brings together many of the best features of other such initiatives, combining job search assistance in the first instance with subsidized job placement for those whom the initial treatment was not successful. As such, a rigorous evaluation of the program may lead to insights regarding the implementation of programs in other countries. In fact, we do find evidence that the program has successfully raised employment, although it is still an open question as to how long-lived these benefits will be.

The program we evaluate was piloted in certain areas before it was "rolled out" nationwide. Moreover, the program has age-specific eligibility rules. We use these area- and age-based eligibility criteria that vary across individuals of identical unemployment durations to identify the program effects. We show how they allow us to examine the extent of substitution between eligible and noneligible groups and also to assess whether there are significant general equilibrium (or "community-wide") effects of the program. We also exploit a number of additional features of our evaluation data to address fundamental problems that have affected nonexperimental program evaluations. First, we use the long history of preprogram data at our disposal to evaluate the plausibility of the assumptions underlying our approach. Having longitudinal data on individuals for up to fifteen years prior to program introduction enables us to place bounds around the maximum and minimum effects of the program based on historical experience. Second, it has been suggested that results from nonexperimental evaluations can be fragile- highly dependent on functional form assumptions and on the availability of suitable conditioning variables. ${ }^{1}$ We use a variety of methods to provide sensitivity analysis on this issue and we find remarkably robust results. Moreover as suggested by Heckman, Ichimura, and Todd (1997) we are able to control for recent labor market history, which can be of central importance for the success of a nonexperimental evaluation.

The program is directed toward individuals aged between 18 and 24 and who have been claiming unemployment insurance (called "Job Seekers Allowance" ${ }^{2}$ in the U.K.) for six months. On average for the 1982-1998 period, these account for about $30 \%$ of all men and $25 \%$ of all women who started a claimant

1. LaLonde (1986) is perhaps the most influential paper expressing this view (see Heckman and Hotz 1989, for an early riposte). Recently, Dehejia and Wahba $(1998,1999)$ have argued that careful matching using propensity score methods can overcome many of the problems with conventional nonexperimental estimators and sought to demonstrate this using LaLonde's original data on the National Supported Work (NSW) program. Smith and Todd (2004), however, showed that such "success" came from discarding a large proportion of the original NSW data and that cross sectional matching estimators remained highly sensitive on the full sample. As with our own results presented here Smith and Todd found difference in differences estimators are the most robust.

2. This is the main British form of unemployment insurance (UI). 
spell within this age group. ${ }^{3}$ The whole program combines initial job search assistance followed by various subsidized options including wage subsidies to employers, temporary government jobs and full time education and training. Prior to this program, young people in the U.K. could, in principle, claim unemployment benefits indefinitely. Now, after six months of unemployment, young people enter the "Gateway," which is the first period of intensive job search assistance. The program is mandatory, including the subsidized options part. In this paper we focus only on the job assistance and wage subsidy element of the New Deal as our data does not cover a sufficient period to analyze the other parts of the program (e.g., education and training). ${ }^{4}$

Our approach to evaluation consists of exploring sources of differential eligibility and different assumptions about the relationship between the outcome and the participation decision to identify the effects of the New Deal. On the "differential eligibility" side, we use two potential sources of identification: age and area. The fact that the program is age-specific implies that using slightly older people of similar unemployment duration is a natural comparison group. This is similar to the identification strategy in Katz (1998) who analyzed the withdrawal of a wage subsidy (the Targeted Job Tax Credit) from economically disadvantaged 23- and 24-year-olds in 1989-1990. He used a combination of age, economic disadvantage, and time in order to construct different comparison groups, and identified a small but significant effect of the program on employment. Our study uses geographical area as an additional source of identification to Katz (1998) by exploiting the fact that the program was first piloted in selected areas before being implemented nationwide.

Under a simple difference-in-differences approach, we show that the choice of the comparison group determines the parameter being estimated as various potential sources of biases are dealt with in different ways. We are especially concerned about substitution and equilibrium wage effects. ${ }^{5}$ Substitution occurs if participants take (some of) the jobs that non-participants would have got in the absence of treatment. Equilibrium wage effects may occur when the program is wide enough to affect wages through changes in the effective supply of labor. While studying the pilot period, we use a diversity of comparison groups who

3. The actual relative size of the long-term unemployed group as defined by the New Deal eligibility rule depends on the state of the economy, being a bit smaller or larger when the economy is undergoing a boom or recession, respectively.

4. For more information about training programs in Britain and their effects see, for instance, Blundell et al. (1997).

5. Until recently the microeconometric literature on labor market policy evaluation has downplayed these "spillover" effects. An exception is Levine (1993) who found significant positive effects on the employment prospects of increases in UI for individuals who were not insured. He used state- and time-specific averages of simulated replacement rates in unemployment equations for noninsured individuals in the CPS and NLSY. Unfortunately, it is unclear in his study whether the impact of these averaged replacement rates is really picking up a change in UI or rather some other omitted state-specific variable. 
will be affected differentially by these types of indirect effects to obtain some indication on the importance of such biases.

We apply a number of different econometric techniques, all exploiting the longitudinal nature of the data set being used but making different assumptions about the structure of the disturbances. A general setup is developed, where all estimators can be interpreted in the light of combined difference-in-differences and matching methodologies. The conditions under which each estimator identifies and estimates the impact of treatment on the treated are derived.

The estimators being used in the present paper, as in many other evaluations, rely on the critical assumption that the evolution of employment in the two groups being compared would have been the same in the absence of the program. ${ }^{6}$ One reason for this to be violated is the fact that individuals eligible for the New Deal program could react to it in anticipation of the program, that is, before eligibility. We can test for this since we observe the complete inflow into unemployment and hence can assess whether the program induces differential behavior in the six months preceding eligibility. Other factors that could induce differential time trends relate to the slight differences either in location or age of the groups to be compared. We use past history to infer the extent to which this may affect our results.

We focus on the change in transitions from the unemployed claimant count to jobs during the first four months of treatment (the "Gateway" period), although we compare this with a slightly longer perspective. We find that the outflow rate to jobs has risen by about $20 \%$ for young men as a result of the New Deal. That is 5 percentage points more men find jobs in the first four months of the New Deal above a preprogram level of 26 percentage points. Similar results show up from the use of different adopted estimators, independently of the amount or type of structure imposed, and they appear to be robust to preprogram selectivity, changes in job quality and different cyclical effects. We obtain similar estimates from using across regional comparison groups (the pilot areas) as we do when using eligible versus noneligible age groups. Such an outcome suggests that either equilibrium wage and substitution effects are not very strong or they broadly cancel each other out.

The robustness of our results is reassuring, but we take care to judge how permanent the effects are likely to be. We do find evidence of an important "program introduction effect" in the sense that the impact of the program is much larger in the first quarter it is introduced than in subsequent quarters. However, there are reasons to suspect that a program such as the New Deal will

6. See Heckman (1979), Heckman and Robb (1986), Blundell, Duncan, and Meghir (1998), Bell, Blundell, and Van Reenen (1999) and Blundell and Costa Dias (2000) for precise descriptions of these conditions. Davidson and Woodbury (1993) is an example of an attempted calibration of substitution effects using data from the Illinois unemployment insurance (UI) experiments (see also Woodbury and Spiegelman 1987 on this program). 
have more sustainable effects than other labor market programs. ${ }^{7}$ First, the program is mandatory: Refusal to participate results in sanctions. Compulsory, sanction-enforced schemes have often been found to be more effective than voluntary schemes. ${ }^{8}$ Secondly, the "disadvantaged youth" we consider are less disadvantaged than those typically treated in typical U.S. programs often found to be ineffective (e.g., ex-offenders). The only entry requirement is six months unemployment benefit claim, which is not so uncommon for those under 25 -years of age in Britain. Finally, we are evaluating the effects of job search assistance and wage subsidies where the U.S. evidence has been more optimistic than for training programs (see Section 5.4 for a more detailed comparison of our results with other studies). ${ }^{9}$

The structure of the paper is as follows. We start in Section 2 with a more detailed description of the New Deal. Section 3 presents the methodology we apply. We discuss how the choice of the comparison group determines the parameter being identified along with the potential sources of bias in each case, and develop a combined difference-in-differences and matching set-up where all the estimators being used can be interpreted. Section 4 describes the data and Section 5 details the empirical results. We separate the analysis of the pilot period of the program, where more detail is possible given the additional instruments we are able to explore to construct the counterfactual. Males and females are also discussed separately and we compare our U.K. results with experimental evaluations of similar U.S. programs. Finally, Section 6 offers some concluding comments.

\section{The Program}

\subsection{Description of the New Deal for the Young Unemployed}

The New Deal for Young People is a recent initiative of the U.K. government to help the young unemployed gain work. The program is targeted at the 18-24-year-old, longer-term unemployed. Participation is compulsory; every eligible individual who refuses to cooperate faces a loss of entitlement to benefits. The criteria for eligibility are simple: Every individual aged between 18 and 24 by the time of completion of the sixth month on Job Seekers' Allowance (JSA), equivalent to UI, is assigned to the program and starts

7. See Card and Hyslop (2002) for evidence of the absence of dynamic effects in the Canadian Self-Sufficiency Program.

8. For example, Knab et al. (2000).

9. On job assistance see the survey by Meyer (1995); on wage subsidies, see Katz (1998). 


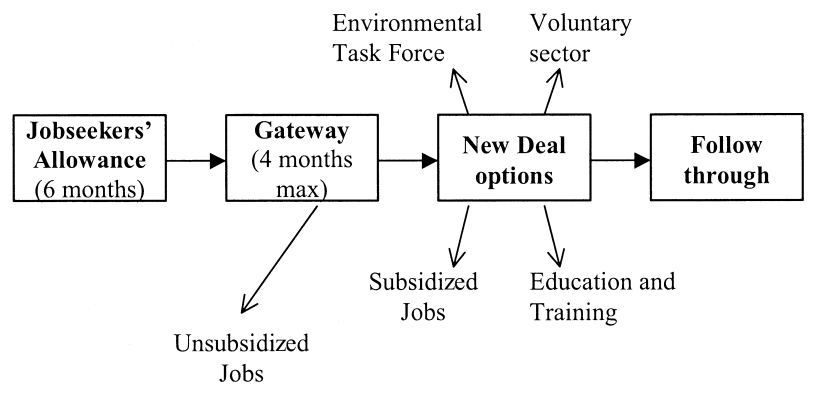

Figure 1. A simplified flow diagram of the New Deal program.

receiving treatment. ${ }^{10}$ Given the stated rules, the program can be classified as one of "global implementation," being administered to everyone in the U.K. meeting the eligibility criteria. ${ }^{11}$ Indirect effects that spill over to other groups than the treatment group may occur and the nature of these effects will be discussed next.

The path of a participant through the New Deal is composed of three main steps (see Figure 1). On assignment to the program, the individual starts the first stage of the treatment called the "Gateway." This is the part of the program being evaluated in the present study. It lasts for up to four months and is composed of intensive job-search assistance and small basic skills courses. Each individual is assigned a "personal advisor," a mentor who they meet at least once every two weeks to encourage/enforce job search.

The second stage is composed of four possible options. First, there is the "employer option" — a six-month spell on subsidized employment. For the subsidized employment option, the employer receives a $£ 60$ (about \$90) per week wage subsidy during the first six months of employment plus an additional $£ 750$ (about $\$ 1,125$ ) contribution to finance a required minimum amount of job training equivalent to one day a week. ${ }^{12}$ Under a second possible option, individuals can enroll in a stipulated full-time education or training course and receive an equivalent amount to the JSA payment for up to 12 months. Third, individuals can work in the voluntary sector for up to six months and are paid

10. JSA is the main form of unemployment benefit in the U.K. It is essentially a flat rate benefit paid every two weeks of about $£ 40$ (\$60) a week. This amount, however, depends on the age of the applicant and household income and needs. Past work experience is not a condition of receipt of JSA although there is a requirement to "actively seek employment." It is not time-limited.

11. Note that certain groups of especially disadvantaged individuals (e.g., the disabled, exconvicts, those with basic skills problems, etc.) are allowed to enter the New Deal earlier than six months if they wish. Additionally, in the early stages of the program those individuals on JSA for over six months were only obliged to enter the New Deal as they reached their 12th, 18th, 24th month, etc. of JSA (unless they choose to be early entrants). We are careful to control for these "early entrants" in the work that follows.

12. This is quite generous. Hales et al. (2000) find that the mean starting wage for those on a subsidized job is $£ 3.78$ an hour, implying a $40 \%$ level of subsidy for a 37 -hour-week. 
a wage or allowance of at least the JSA plus $£ 400$ (\$600) spread over the six months. Finally, they may take a job on the "Environmental Task Force"essentially a government job. ${ }^{13}$

Once the option period is over, if the individual has not managed to keep/find a job or leave the claimant count for any other reason, the third stage of the program is initiated, the "Follow-Through." This is a process similar to the Gateway, taking up to 13 weeks, where job-search assistance is the main treatment being provided.

The program was launched in the whole U.K. in April 1998 (the "National Roll-Out"). There was, however, a pilot from January to March 1998, when the program was implemented in 12 areas, called the Pathfinder pilots. ${ }^{14}$ Clearly, identification of the treatment effect under these conditions requires stronger assumptions than when an experiment is run within regions using random assignment over a large number of areas. As will be discussed, the problem relates to the fact that the counterfactual must either be drawn from a different labor market or from a group with different characteristics operating in the same labor market. Next we explore what we can identify under different assumptions.

Given that the program has not been running for a long period, we focus in this paper on an evaluation of the Gateway. In particular, we are concerned with the degree to which enhanced job search assistance has lead to an increase in outflows to jobs. The evaluation is based on data provided by the Pathfinder areas before the National Roll-Out of the program, as well as on data available following the National Roll-Out.

\subsection{Choice of the Outcome Variables}

We focus on the impact of the program on the proportion leaving unemployment within four months of entering the Gateway. The choice is mainly dictated by the desire to focus on the stated government targets and the paucity of data on individuals after they have finished the options. ${ }^{15}$ However an alternative outcome variable would have been the proportion leaving unemployment within, say, eight or ten months of entering the unemployment pool. This outcome variable would avoid the potential composition effects that may be induced by the anticipation of the program among eligible individuals. In

13. The intention was that the treatments were staged. The employment service would seek to place an individual in an unsubsidized job in the first month of the program, a subsidized job in the second month, in education/training in the third month and the Environmental Taskforce in the fourth month. This guidance was not strictly enforced on the ground, however.

14. See Anderton, Riley, and Young (1999).

15. Our data currently ends in July 1999. Individuals entering the Gateway in April 1998 and joining the year-long education and training option after four months will only start job search in August 1999. 
particular, if the program is perceived as being able to improve placements, then individuals close to the Gateway and eligible for the program may reduce their search effort and wait for the program. In this case, the average individual among eligibles would be more prone to leave unemployment than its counterpart in the comparison group, leading to increased exit rates for this group. However, we can test this hypothesis by estimating the proportion of those who left unemployment by the end of the sixth month in the eligible and ineligible group. Such a comparison will provide an idea of how important such compositional effects are likely to be.

We will pay special attention to the outflows into employment, but we also examine total outflows from unemployment to all destinations. To assess the importance of the estimated effects, we interpret them in an historical perspective. We provide some lower and upper bounds for the treatment effect by using our methodology during other preprogram time periods. This can be done for total outflow for all years since 1982 .

To summarize: Treatment is understood as the job search assistance initiative of the New Deal and the treated are those who enroll in the program after completing a six-month unemployment spell. We aim at measuring the impact of improved job-search assistance on the probability of finding a job among the treated. To assess the robustness of our results, we also present estimates of other parameters that are informative about the adequacy of the underlying assumptions. Different definitions of treatment and the treated often characterize such parameters, and this is made clear in the following discussion.

\section{Identification and Estimation Methods}

Our approach to estimate the impact of the New Deal program relies on using information from the pilot period as well as information from the National Roll-Out. The New Deal can affect employment of both eligible and ineligible individuals in a number of ways. First the eligible individuals receive job search assistance that may enhance their ability to find a job. Second, some of the individuals who pass through the Gateway will receive the wage subsidy option, reducing the cost of employing them for an initial period of six months. This wage subsidy will expand the employment of such workers but may also lead to a substitution of other workers for these cheaper ones. The extent to which this may happen will depend on a number of factors. If the subsidy just covers the deficit in productivity as well as the costs of training, we would not expect any substitution; these workers are no cheaper than anyone else. Second, it will depend on the extent that these workers are substitutable in production for existing workers and on the extent that it is easy to "churn" workers, that is to replace a worker finishing a six-month subsidy with a new subsidized worker. 
The latter is an important point, since the subsidy only lasts six months. Moreover the agencies implementing the New Deal are supposed to be monitoring the behavior of firms using wage subsidies and employing individuals on the New Deal. Of course if job durations are generally short, firms will be able to use subsidized workers instead of the nonsubsidized ones, without any extra effort.

The New Deal may also change the price of labor in a region or country as a whole as it affects a substantial number of people. For example, the increased search activities of the unemployed could lower the equilibrium wage for less skilled individuals and therefore increase aggregate employment through a higher job offer arrival rate. This will tend to increase employment for eligible and ineligible individuals and will counteract the effects of substitution on the nontreatment group. Randomized trials cannot account for these general equilibrium or "community-wide" effects, which have become an important issue in the program evaluation literature. ${ }^{16}$

Assessing the importance of substitution and of general equilibrium effects through wages or other channels is of central importance. Using the comparison between the pilot and control areas as described next, and assuming these areas are sufficiently separate labor markets from each other, we will be able to assess the extent to which substitution and other general equilibrium effects combined are likely to be important side effects of the program, at least in the short-run. Next we discuss the evaluation methodology, a central part of which is the choice of comparison group. This choice is to a large extent governed by the issues previously discussed.

\subsection{The Choice of Comparison Group}

Define by $Y_{i t}^{1}$ the outcome for individual $i$ in period $t$ they are exposed to the policy (treatment). The outcome for the same individual if not exposed to the policy is $Y_{i t}^{0}$. Consequently the impact for the $i$ th individual of the policy is $Y_{i t}^{1}-Y_{i t}^{0}$. The average policy impact for those going through the New Deal is $E\left(Y_{i t}^{1}-Y_{i t}^{0} \mid N D=1\right)$, where $N D=1$ denotes the treated. Quite clearly, the evaluation problem relates to the missing data that would allow us to estimate $E\left(Y_{i t}^{0} \mid N D=1\right)$ directly. We now define a number of alternative comparison groups that can be used to estimate this counterfactual mean. As we will point out, the definition and interpretation of the estimated parameter will depend on the comparison group.

Consider first contrasting the employment growth in pilot and control areas. Thus, $N D=1$ and $N D=0$, designate the pilot and control areas, respectively. Let $t=0$ represent the period before implementation and $t=1$ the period after.

16. For example, Heckman, Lochner, and Taber (1998). 
By assuming the same growth in employment in both areas in the absence of the policy, hereafter designated the common trends assumption, the missing counterfactual value can be replaced by,

$$
\left.E\left(Y_{i t}^{0} \mid N D=1, t=1\right)\right)=E\left(Y_{i t}^{0} \mid N D=1, t=0\right)+m_{t}
$$

where $m_{t}$ is the aggregate employment growth in the non-treated areas,

$$
m_{t}=\left\lfloor E\left(Y_{i t}^{0} \mid N D=0, t=1\right)-E\left(Y_{i t}^{0} \mid N D=0, t=0\right)\right\rfloor .
$$

This gives rise to a straightforward difference-in-differences estimator. Under the assumption of common trends stated previously, a comparison of growth rates estimates the impact of the New Deal on individuals residing in a pilot area, irrespective of whether they are eligible or not. Hence this comparison estimates the net effect of the program including any impact of general equilibrium effects and substitution.

The definition of the comparison group is of course central to the evaluation. Instead of comparing exposed and nonexposed areas during the pilot period, we could use the approach described above to compare eligible and noneligible individuals following the implementation of the New Deal in the area. We explore the cutoff age for eligibility and redefine $N D$ to represent the individual's eligibility status following implementation in the area. More specifically, $N D=0$ refers to ineligible individuals "similar" to the eligible ones, that is, those unemployed for over six months whose age is just above 24 living in areas that have been treated. The choice of this group makes it most likely that their overall characteristics and behavior match that of the treatment group; that is, that the growth rate of employment for the two groups would be similar in the absence of the program. Such an approach is similar to a regression discontinuity design. ${ }^{17} \mathrm{By}$ applying the common trends assumption to these two groups, we are ruling out any substitution or equilibrium wage effects that impact on the groups in a differential way. In this case a comparison in the growth rates between eligible and ineligible individuals will provide an estimate of the impact of the program on the eligible ones. A main advantage of this approach is that it can be used both in the Pilot and in the National Roll-Out periods, extending the time length of the empirical analysis.

The virtue of the comparison group - that it is very similar to the treatment group in terms of its characteristics and will therefore be expected to respond to shocks in similar ways-may be, in fact, its greatest disadvantage. The substitution effects are likely to be much more severe the closer are the productivity characteristics of two groups. In the event of substitution, the impact of the program for the eligible group is biased upwards by the fact that the employment of the comparison group is decreasing. If such a decrease is, say, $\beta$, the

17. See Hahn, Todd, and Van der Klaauw (1999). 
"true" net increase in employment is $2 \beta$ lower than the estimated increase in employment. However the benefit in terms of employment for the target group would be $\beta$ lower than our estimate. Within this framework of analysis, the only way we have of gauging the size of $\beta$ is through the pilots using both sources of identification discussed above and comparing the obtained results, which are differently affected by substitution.

An important issue is whether the impact of the policy is heterogeneous with respect to observable characteristics. If this is the case, we should interpret the estimate we obtain as an average impact across different effects but must make sure that a suitable comparison group exists. One way to address this problem is to use propensity score matching adapted for the case of differencein-differences. In this case, there are two assignments that are nonrandom. One assignment is to the eligible population and the other assignment is to the relevant time period (before or after the reform). For the evaluation to make sense with heterogeneous treatment effects, we must guarantee that the distribution of the relevant observable characteristics is the same in the four cells defined by eligibility and time. One way of achieving this is to extend propensity score matching by defining two propensity scores-one for eligibility and one for time period. We then create a matched sample based on the two propensity scores using the following assumption (see Dearden et al. 2001),

$$
\begin{aligned}
& E\left(Y_{i t}^{0} \mid P_{E X}, P_{t X}, N D=1, t=0\right)-E\left(Y_{i t}^{0} \mid P_{E X}, P_{t X}, N D=1, t=1\right) \\
& \quad=E\left(Y_{i t}^{0} \mid P_{E X}, P_{t X}, N D=0, t=0\right)-E\left(Y_{i t}^{0} \mid P_{E X}, P_{t X}, N D=0, t=1\right)
\end{aligned}
$$

where $N D=1$ denotes eligibility, $t$ is the time period, and $P_{E X}=\operatorname{Pr}(N D=1 \mid X)$ and $P_{t X}=\operatorname{Pr}(t=1 \mid X)$ are the propensity scores for eligibility and being observed in $t=1$, respectively. This allows the time effects to differ by $X$ and ensures that the distribution of observed characteristics is balanced across all cells. The observables we use include, among other things, labor market history. We implement this approach both parametrically and nonparametrically (see the estimation section below).

Finally the discrete nature of our outcome variable may imply that the assumptions we make do not hold for the expectations (which are employment probabilities) but for some transformation thereof; in particular for the inverse of the probability function, which must be assumed known. In this case the common trends assumption should be imposed on the inverse probability function, $f^{-1}$,

$$
\begin{aligned}
f^{-1}\left\lfloorE \left( Y_{i t}^{0} \mid X\right.\right. & , N D=1, t=1)\rfloor-f^{-1}\left\lfloor E\left(Y_{i t}^{0} \mid X, N D=1, t=0\right)\right\rfloor \\
& =f^{-1}\left[E\left(Y_{i t}^{0} \mid X, N D=0, t=1\right)\right]-f^{-1}\left[E\left(Y_{i t}^{0} \mid X, N D=0, t=0\right)\right]
\end{aligned}
$$

This just says that the assumption we make is valid for the index rather than the 
probability itself. Define by $Y_{i t}$ the employment indicator for individual $i$ in period $t$. It represents the outcome under treatment when $N D=1$ and $t=1$, and is the outcome under nontreatment in all other cases. The impact of the policy can then be evaluated as

$$
\begin{aligned}
I(X)=E\left(Y_{i t} \mid X, N D=1, t\right. & =1) \\
& -f\left\lfloor f^{-1}\left(E\left(Y_{i t} \mid X, N D=1, t=1\right)-\alpha(X)\right)\right\rfloor
\end{aligned}
$$

where

$$
\begin{gathered}
\alpha(X)=\left\{f^{-1}\left[E\left(Y_{i t} \mid X, N D=1, t=1\right)\right]-f^{-1}\left[E\left(Y_{i t} \mid X, N D=1, t=0\right)\right]\right\} \\
-\left\{f^{-1}\left[E\left(Y_{i t} \mid X, N D=0, t=1\right)\right]-f^{-1}\left[E\left(Y_{i t} \mid X, N D=0, t=0\right)\right]\right\}
\end{gathered}
$$

$I(X)$ is then averaged using as weights the distribution of $X$ among actually treated individuals. Despite the similarity to the linear case, the nonlinear assumption stated above entails two additional restrictions on the nature of the error terms: only group-effects are allowed for and the groups being compared are assumed to have the same residual variance.

\subsection{Implementation}

Given a particular choice of comparison group, all methods we apply have the same structure as implied by (2) and (3). They differ only in the way that the expectations in these expressions are computed.

In the linear matching difference-in-differences estimator we run the following simple regression on the sample of comparison and treatment observations

$$
Y_{i t}=\theta_{N D}+d_{t}+\gamma^{\prime} X_{i t}+\alpha N D_{i t}+\varepsilon_{i t}
$$

where $Y_{i t}$ is a discrete variable indicating whether the person is in employment or not, $\theta_{N D}$ is an eligibility specific intercept (it may be defined over area or age or both, depending on the comparison group used), $d_{t}$ reflects common/aggregate effects and where $X$ is included to correct for differences in observable characteristics between individuals and areas registered at the eligibility point (completion of the sixth month in unemployment).

These procedures can be quite restrictive in a number of ways. First, they do not allow for $\alpha$ to depend on $X$. Second, they do not impose common support on the distribution of the $X \mathrm{~s}$ across all four cells. The first assumption can be relaxed under the parametric setting, and this is what we do within the nonlinear logit specification. The effect of treatment is allowed to depend on the observable characteristics of the agents by applying the following estimation technique. A different relationship between the outcome and the observables is estimated by group of agents-eligibility status (area or age) interacted with 
time. Such relationships entail the particular behavior pattern of each group and the impact of treatment when it existed. By predicting the outcome of the treated using the untreated behavioral equation one obtains an estimate of how the treated would have behaved without the treatment, conditional on their observable characteristics. Applying difference-in-differences to such predictions using Equation (2) produces an estimate of the expected impact of treatment on the treated.

To relax both assumptions simultaneously, we supplement the above results by propensity score matching. As mentioned previously, this involves matching on two propensity scores, which balances the distribution of the $X$ characteristics in the treatment and comparison samples, before and after the reform. The matching method we use smooths the counterfactual outcomes using splines (see Heckman, Ichimura and Todd 1997 and Meghir and Palme 2003). ${ }^{18}$ As before, we also transform the outcome applying the logit transformation to estimate the impact of the New Deal under a nonlinear specification. ${ }^{19}$

As discussed before, the Pilot study provides an additional instrument in the definition of the comparison group on the top of the age eligibility rule, namely region. We have used it to construct two possible comparison groups: The first takes all eligible individuals living in all non-Pathfinder areas; the second selects all eligible individuals in the set of non-Pathfinder areas that most closely resemble the Pathfinder areas in a way detailed next. The goal of a careful choice of the comparison area is to satisfy Assumption (1), which requires common trends. To assess how similar two groups being compared are, we contrast their recent history of conditional outflows from unemployment. Figure 2 illustrates the evolution of the outcome of interest for men aged 19-24 years old living in Pathfinder and all non-Pathfinder areas. It is clear that the Pathfinder areas have, on average, worse labor market conditions. The older group aged 25-30 and living in Pathfinder areas is also presented as an alternative comparison. ${ }^{20}$ This group tends to have lower outflows than their younger counterparts. However, what is important is that the difference between the treated and comparison curves is kept nearly constant over time to guarantee that macrotrends affect the two groups in similar ways. These data show that the size of the estimated impact can be sensitive to the choice of the comparison

18. Under the smoothing splines method, we run a regression of the outcome of interest on a cubic polynomial of the two propensity scores for each of the comparison groups. Predictions of the outcome under the three nontreatment cases for each of the matched treated observations under the nearest neighbor method are then computed and used to estimate the impact of treatment.

19. We also computed the same estimates using a Kernel and the nearest neighbor weighting schemes. The obtained estimates are similar although less precise, particularly under the nearest neighbor approach. Results can be found in Blundell et al. (2003).

20. We also considered more finely disaggregated age groups-e.g., 24- vs. 25-year-oldswhich generates similar qualitative results, although with much less precision on account of the smaller sample size. 


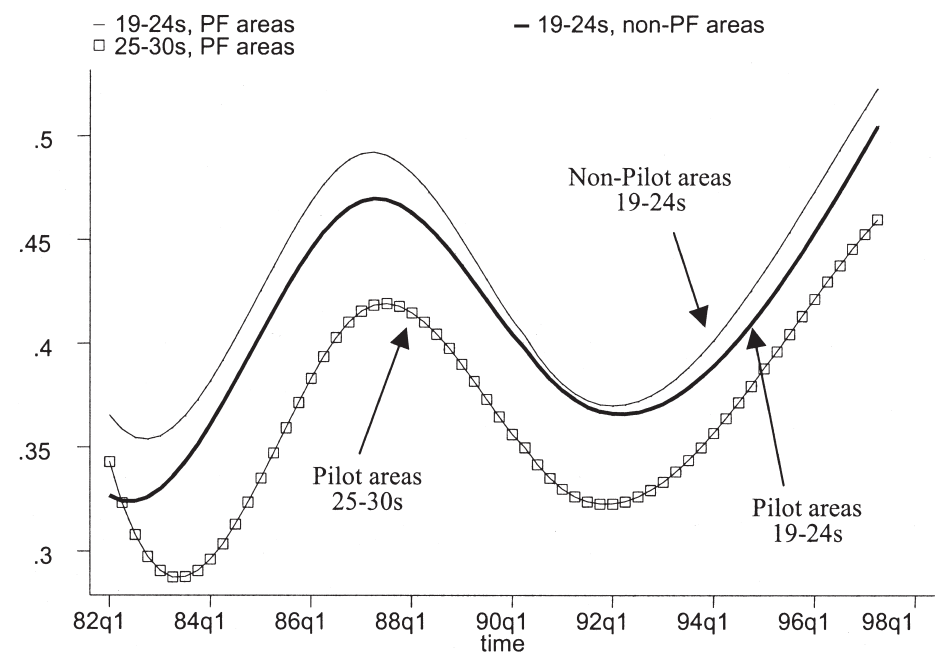

FiguRE 2. Outflows from JSA conditional on completing six months effect by the end of the 10th month on JSA. This graph illustrates the proportion of men leaving unemployment between the sixth and tenth months of unemployment 1982-1998. "PF" indicates that the men were living in a Pathfinder Pilot area (prior to New Deal introduction in 1998). The data have been smoothed by a cubic spline in time. Breakpoints were included at the first quarter of 1987 and the first quarter of 1990. No other covariates were considered.

period. Hence, in the results section we are careful to test the sensitivity of the results to alternative timing assumptions.

Instead of assuming the two historical curves in Figure 2 for individuals in Pathfinder and non-Pathfinder areas are parallel, we can choose the nonPathfinder areas that more closely follow the cycle pattern identified for the Pathfinder areas. This can be done either within each of the matching procedures described above, or prior to them, selecting the areas where the comparisons are to be drawn from. We have chosen to adopt this latter option, matching the areas in a first step and applying all types of estimators comparing eligibles in different areas to the subsamples obtained. In this procedure, we have applied a completely nonparametric technique using a quarterly time series of the outcome variable from 1982 to just before the introduction of the New Deal, in January 1998. A measure of distance was then computed for each possible pair of Pathfinder and non-Pathfinder areas and the two nearest neighbors were chosen. Once this is done, we carry out the estimation procedure as described earlier.

\section{Data}

The data are drawn from the publicly available 5\% longitudinal sample of the whole population claiming Job Seekers Allowance (JSA) in the U.K. from 1982 
to July 1999 (the JUVOS database). This is an administrative database that includes individual information on spells on JSA, the unemployment benefit available in the UK, the main focus being the starting and ending dates of the spells. Individuals can be followed through all their JSA spells since the same group of the population is followed over time. However, although we know the length of time in non-JSA spells, we have no information on any transitions between different jobs during these periods. Since 1996, however, the agencies have collected data on the destination when leaving the claimant count. There are twenty different destination codes, including exit to employment, training/ education, other benefits, incarceration, etc. The JUVOS data set also includes a small number of other variables-age, gender, marital status, geographic location, previous occupation, and sought occupation. ${ }^{21}$

We also make use of the New Deal Evaluation Dataset (NDED), an administrative data set that contains information on virtually all individuals that have gone through the New Deal, even if only briefly. For participants, very detailed information is available from the time they join the program, including the types of treatment being administered and the timing of each intervention, letters being sent and interviews being made, a long list of sociodemographic variables and the destination when leaving the program. Nonparticipants, however, are not included in the sample, which limits its use for evaluation purposes. Note that we only consider the flow at 6 months, so there is no direct problem with mixing the stock and flow.

The use of the evaluation dataset (NDED) is meant to complement the lack of information in benefit (JSA) administrative records about the take-up of New Deal options. Since starting an option implies dropping from the JSA claimant count, there is a potentially large group that is being reclassified as nonunemployed while simply being driven through the program according to its rules. Unfortunately, we are unable to securely identify these types of exits from the JUVOS data set. ${ }^{22}$ We use the NDED instead to know the proportion of participants that enroll in each type of option (in any given region-date) by length of the New Deal spell.

In drawing up the treatment groups we have used 19-24-year-olds even though the New Deal also affects 18 year olds. This is because 18-year-olds can still be in high school and in England high school is only compulsory up to the age of 16. Participation of 16-18-year-olds in full-time education grew rapidly over this period so we decided to avoid any time varying

21. Descriptive statistics on the treatment groups and different comparison groups before and after matching show that matching significantly improves the similarity between the treated and the controls. Results can be found in Blundell et al. (2003).

22. There is a code in the JUVOS data that purports to have New Deal destinations, but on investigation it proved to be unreliable. 


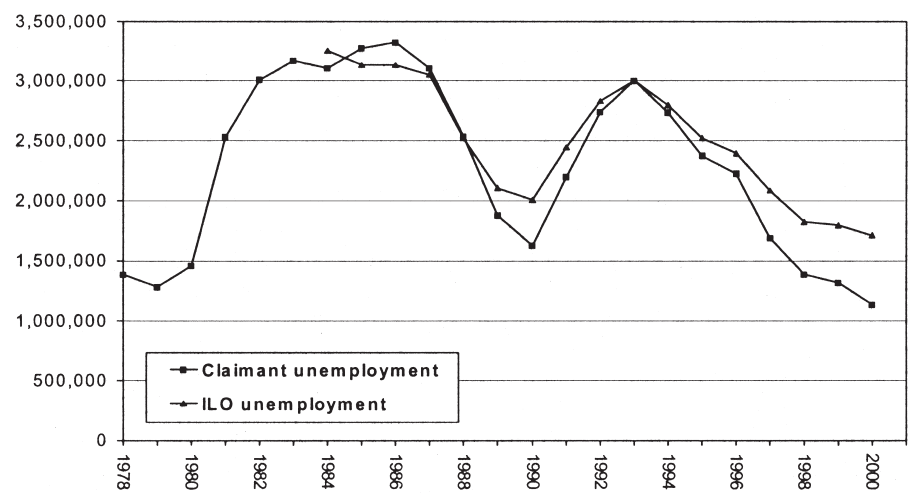

FIGURE 3. Unemployment-claimant and ILO measures. Data on ILO (International Labor Organization) defined unemployment were taken from the Labor Force Survey and claimant count unemployment taken from Labor Market Trends (various years). The ILO definition is based on asking out of work individuals whether they would be available and prepared to accept a job within two weeks. The claimant count is the number of people who are receiving unemployment benefit (called Job Seekers Allowance since 1994). Although the series track each other relatively well, there will be some people who are ILO unemployed who will not be in the claimant count (e.g., if they left their job voluntarily this will disqualify them for benefit receipt for a period of time). Similarly some individuals could be claiming unemployment benefit without genuinely searching for a job.

composition effects by dropping 18-year-olds. In any case, inclusion made no difference to the results. ${ }^{23}$

The historical period we are examining is partly dictated by the data. The current JUVOS data ends in July 1999. For the National Roll-Out we consider all individuals who finished a six-month JSA spell between April and December 1998 and then follow them up to four months later (so our end date is April 1999). We match this with the individuals who finished a six-month JSA spell between April and December 1997. For the Pilot Study we compare individuals completing a six-month JSA spell between the start of January and the end of March 1998 in the Pathfinder areas to the same group in January through March 1997. Ending the sample in April 1999 has the advantage that we avoid contaminating the New Deal effect with the introduction of the National Minimum Wage enforced from April 1999 onwards. $^{24}$

Some information on the macroeconomic climate is given in Figure 3. The New Deal was introduced at a favorable point of the business cycle by historical standards. There was no rapid improvement in the labor market between Spring

23. One could also worry about $18-22$-year-olds in college education. There is only a tiny fraction of this group in the unemployed pool, however.

24. Britain had never had a national minimum wage before this date. There was a system of Wages Councils that set minimum wages for certain groups of occupations in low wage industries. These only covered about 2 million of the approximately 30 million U.K. workforce when they were abolished in 1993 (see Dickens, Machin, and Manning 1999 for an analysis). 
1998 and 1999, however, unlike the previous 12 months. The changing business cycle illustrates the reason why we have to select our comparison groups carefully in implementing our approach to ensure that these macrotrends are "differenced out." 25

\section{Results}

This section presents estimates of the impact of the Gateway on the flows into employment. We analyze men and women separately given the different composition of the two groups and characteristics of their behavior. We start by considering men during the pilot period in Section 5.1, and discuss the different possible estimates and respective underlying assumptions available. Section 5.2 presents the results obtained for men during the National Roll-Out, establishing a comparison with what the estimates were for the pilot period and assesses their robustness. Section 5.3 presents the results for women and Section 5.4 compares the magnitude of our results with those from similar U.S. programs.

\subsection{Pilot Study: Men's Results}

Table 1 presents the main estimates of the impact of the Gateway on eligible men living in Pathfinder areas during the pilot period and Table 2 presents some descriptive statistics on the raw flows. We consider a number of different possible comparison groups, providing some insight on the possible size of indirect effects. Each row in the table corresponds to a different comparison, including different estimates, obtained under different methods, of the effects of the Gateway on outflows to employment after four months of treatment. ${ }^{26}$

The first row of Table 1 compares men aged 19-24-years-old with the same unemployment duration and living in Pathfinder and all non-Pathfinder areas. After four months of treatment, it is estimated that the Gateway has improved participants' exits into employment very significantly-all the estimators point to an impact of about 10 to 11 percentage points. This effect is even more impressive if compared with the outflow rates reported in Table 2. In the preprogram period only $24 \%$ of individuals in the treatment group obtained employment over the similar four-month period (compared to $33 \%$ afterwards). Thus, the improved job-search assistance provided during the Gateway seems to

25. Clearly, the effects of the program in this favorable climate may not apply to less favorable periods as the composition of the unemployment pool changes and so do the agents' attitudes.

26. All regressions include a set of other covariates, including age (when similar age groups are being compared), marital status, region, sought occupation and labor market history variables. All computations have been performed excluding these covariates as well. Given the similarity of the results, however, we skip their presentation. 


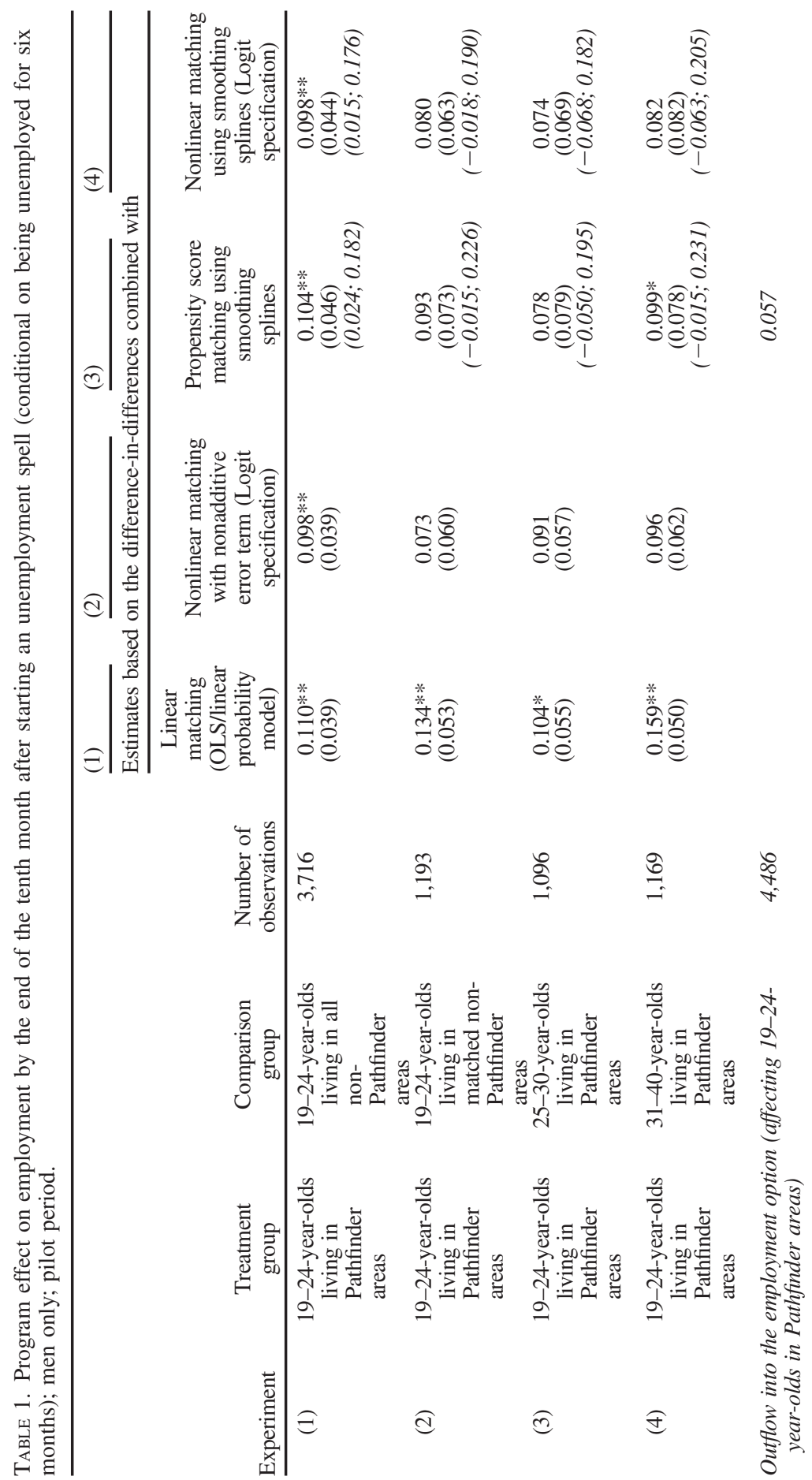




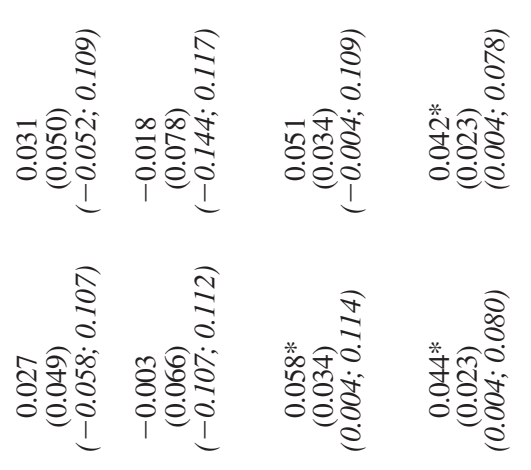

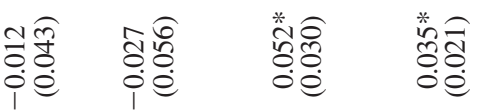

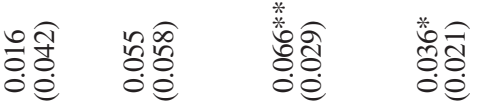

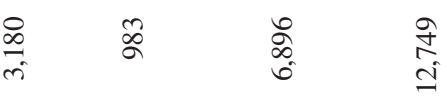

年

i $\quad$ (1)

㝕

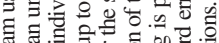

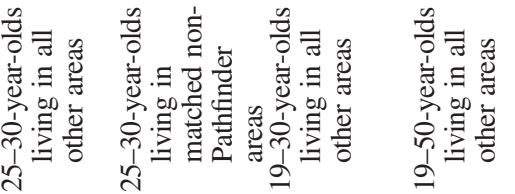

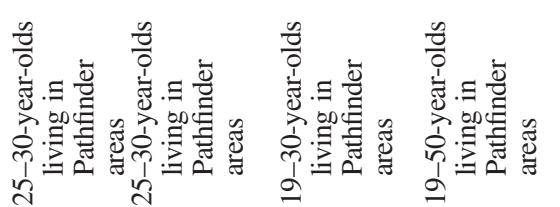

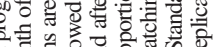

秛

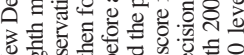

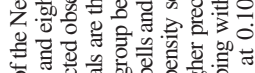

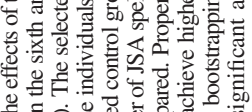

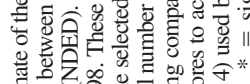

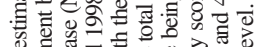

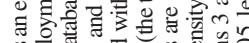

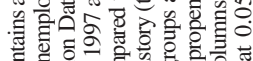

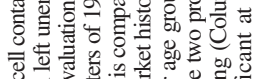

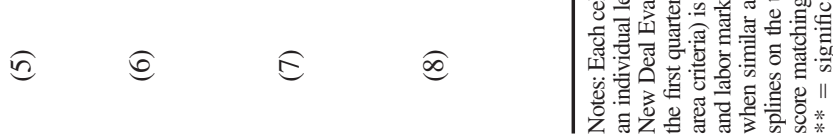


TABLE 2. Flows from the claimant count into employment by the end of the tenth month since starting an unemployment spell (conditional on being unemployed for six months); men only.

Flows by the end of the 10th month on JSA

\begin{tabular}{lccc} 
& on JSA & & \\
\cline { 2 - 4 } & $\begin{array}{c}\text { Before the } \\
\text { program }\end{array}$ & $\begin{array}{c}\text { After the } \\
\text { program }\end{array}$ & Difference \\
\hline Pilot period & & & \\
Treatment group: 19-24-year-olds in Pathfinder areas & 0.241 & 0.330 & +0.089 \\
Comparison group: 19-24-year-olds in all other areas & 0.271 & 0.250 & -0.021 \\
Comparison group: 19-24-year-olds in matched non- & & & \\
$\quad$ Pathfinder areas & 0.228 & 0.233 & +0.005 \\
Comparison group: 25-30-year-olds in Pathfinder areas & 0.276 & 0.260 & -0.016 \\
National Roll-Out & & & \\
$\quad$ Treatment group: 19-24-year-olds & 0.258 & 0.281 & +0.023 \\
Comparison group: 25-30-year-olds & 0.230 & 0.199 & -0.031 \\
\hline
\end{tabular}

Notes: The data are taken from the JUVOS 5\% longitudinal sample of all unemployed (JSA claimants). Selected observations are those individuals completing a six-month spell on JSA over a predefined time interval. Individuals satisfying this criterion are then followed up to the end of the eighth and tenth months of unemployment to check whether they have found a job. The present table considers the first quarters of 1997 and 1998 for the "Pilot period" estimates and the second to fourth quarters of 1997 and 1998 for the "National Roll-Out" estimates. The eligible group (defined by the age and area criteria) is compared with the selected control group.

have raised the probability of getting a job by about $42 \%(=10 \% / 24 \%)$ after four months of treatment.

Of course, this result should be contrasted with the information from the NDED concerning outflows into the employment option (the wage subsidy that may be offered to those who have not found employment through job assistance). It is estimated that the outflows into an employment option after 4 months of treatment sum up to 5.7\% of men joining the Gateway (see Table 1). Subtracting this off the overall New Deal effect would give a "pure" Gateway impact (on outflows to unsubsidized employment) of about 4 to 5 percentage points. But this is likely to be a lower bound. The calculation assumes that there is essentially no deadweight of the employer subsidy. This happens under the assumption that participants can be split into groups according to their ability to find a job, and that subsidized jobs are being attributed to those in need of a subsidy to leave unemployment. If, on the other extreme, it is believed that the subsidized jobs are being allocated to the most employable participants, then the amount of scaling down required might be small and the "true" effect would be closer to the full 10 or 11 percentage points. Thus, four percentage points is a lower bound for the pure Gateway/job assistance effect. The method used to estimate the impact of treatment does not seem to substantially influence the results, reflecting some robustness of the estimates to the functional form assumptions. By restricting the comparison group to eligible men living in matched non-Pathfinder areas does not change the results either (row 2). Depending on the method used, the estimated effect may rise or fall slightly, but 
not significantly so, supporting the comparability of the two groups used in row 1 .

The rest of the rows in Table 1 present estimates for some of the other identifiable parameters discussed in Section 3, providing further evidence on the robustness of the results and informing about the importance of indirect effects. We start by using our second main source of identification, the age-based eligibility criterion, and compare eligible and ineligible men aged 25-30-yearsold within the Pathfinder areas. We emphasized before that this estimate is based on different assumptions from the estimates in rows 1 and 2. In fact, it may suffer from substitution more acutely and it is not immune to local labor market wide wage effects. However, the age-based point estimates in row 3 are very close and insignificantly different from the area-based estimates in row 1 . The linear matching estimator, for example, suggests a treatment effect of 10.4 percentage points when 25-30-year-olds are used as the comparison group (row 3 ) compared to 11 percentage points when 19-24-year-olds in non-Pathfinder areas are used as a comparison group (row 1). Hence, we cannot reject the simple null hypothesis of a model without substitution and equilibrium wage effects. Alternatively, their effects may cancel out, the relative sizes of the substitution and wage effects being very similar. We further test for substitution using the older group of 31-40-year-olds living in Pathfinder areas as a comparison group. This group is expected to be less substitutable for 19-24year-olds than the younger 25-30-year-olds comparison group. Under this assumption, and given that substitution exacerbates the impact of the program, we would expect this estimate to be lower than the one presented in row 3. But row 4 presents estimates of the 4-month effects of the New Deal that, if anything, are higher than the previously presented results. This is not consistent with large substitution effects.

Another way to perceive the importance of substitution is to apply the common trends assumption separately to eligible and ineligible individuals and compare the growth in the employment in pilot and control areas for each of the two groups. Substitution effects should increase the employment of eligible individuals at the expense of ineligible ones in the pilot areas. Area-specific general equilibrium effects due to the fall in wage pressure from the increased effective supply of workers should tend to increase the employment of both eligible and ineligible individuals. The general equilibrium effects can be though of as part of the program effect. The employment growth of eligible individuals will include the "pure" program effect, the general equilibrium effect and the presumably positive substitution effect. The employment growth of ineligible individuals in the same area will include a general equilibrium effect and a substitution effect of equal and opposite sign to that of the treatment group (assuming that the comparison group is the only group of workers displaced due to the wage subsidy). Thus, a sum of the estimated "treatment" 
effects on eligible and ineligibles in the pilot areas compared to the control areas (weighted by the size of each group) should provide us with an estimate of the program effect and the general equilibrium effect combined, but the net of any substitution. If this is similar to an appropriately scaled version of the effect on eligibles alone, we can infer that substitution effects are not an important issue.

Rows 5 and 6 of Table 1 present results from the comparison of ineligible individuals living in Pathfinder and non-Pathfinder areas: no significant effects of the New Deal on noneligibles are found. Finally, rows 7 and 8 contain estimates of the employment effect in the "whole market." Men aged 19-30 and 19-50-years-old and living in Pathfinder areas are compared with similar individuals living in non-Pathfinder areas. The results only confirm what has been established before: during the pilot period, the program had a very significant positive impact on outflows to employment in the markets it has been implemented. As anticipated, the point estimates are smaller given the relative size of the treatment group in the market, but in the expected proportion.

The relative size of the estimated impact of the program, when viewed in an historical perspective, can further inform on how significant the result is. In order to do so, we computed the series of year-by-year estimates of the impact of a fictitious program. ${ }^{27}$ Given the lack of data on "destination when leaving JSA" before August of 1996, we use information on "outflows to all destinations" to perform this analysis. Suppose, for instance, that the estimated effect of the New Deal Gateway lies within typical values of the historical estimates. This might be an indication that such result is determined by some differential aggregate variation that is not being controlled for and is captured by the program dummy. In such a case, doubts are raised on whether the estimated effect is actually capturing the causal effect of the program alone. To this end, Figure 4 considers different types of comparisons and plots the estimates of nonexistent programs over time. The first panel in the chart compares eligible individuals living in Pathfinder areas with eligible individuals living in all other areas. The size of the New Deal effect, represented by the last point in the graph, is well above all other estimates for previous periods and is the only one that is statistically significant at the $5 \%$ level. This is just more evidence that the effects of the program on participants during the pilot period are very positive. Panel 2 compares participants with eligible individuals living in matched non-Pathfinder areas. It shows a similar pattern but with a stronger effect of the New Deal, which may be a consequence of the higher volatility observed. Panel 3 and 4

27. This analysis is also informative on whether the assumptions on the comparability between any two groups being used are valid. In fact, before the introduction of the New Deal the estimated impacts are expected to be zero given the absence of a policy that causes a differential behavior between any two groups being compared. If, however, a large number of point estimates are found to be significantly different from zero, one might suspect that the assumptions on the comparability of the two groups being used are not valid. 

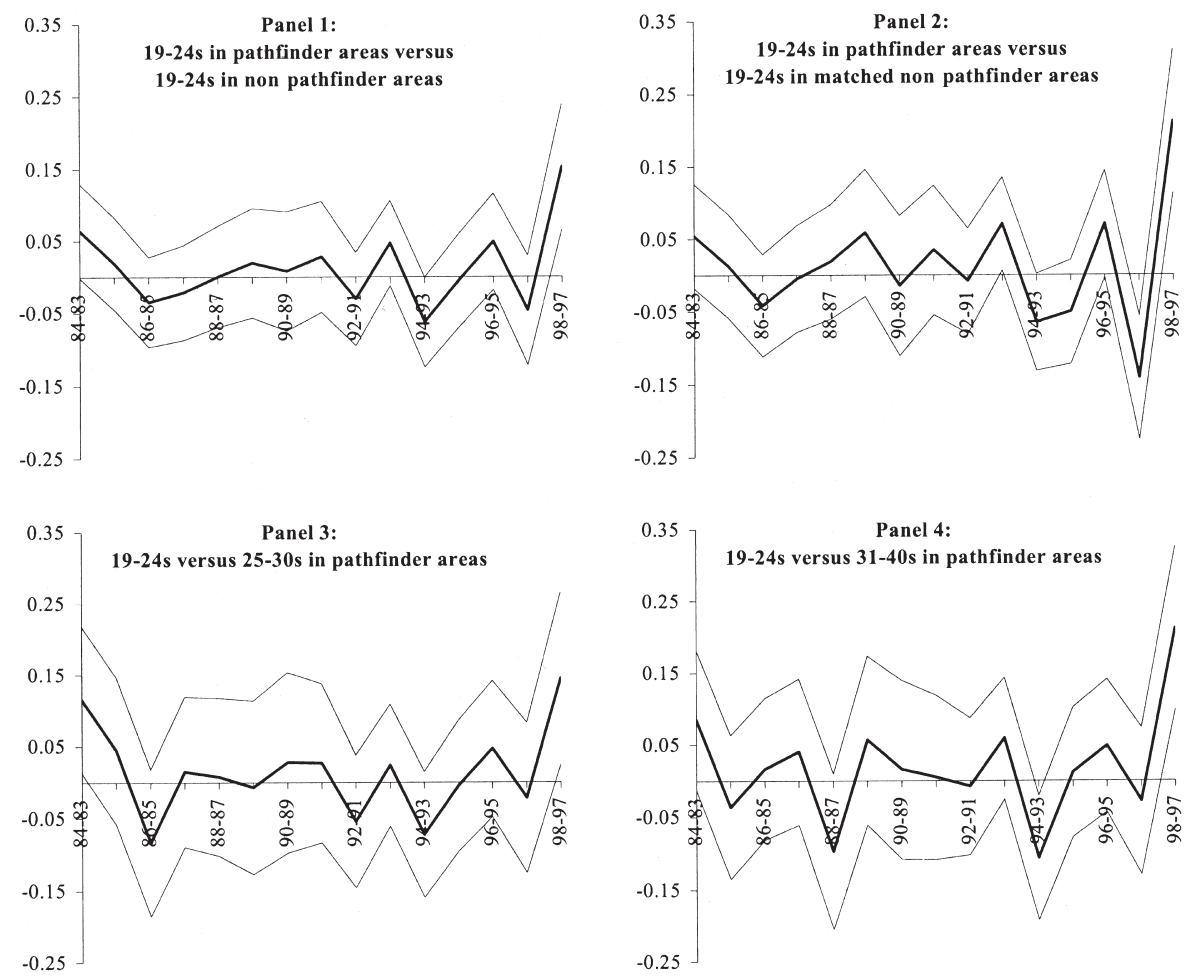

FiguRE 4. Difference in differences over time outflows to all destinations; men only. Each panel presents the year-by-year difference in difference estimates of the impact of "fictional" programs on the total outflows from unemployment within 4 months of completion of the sixth month of unemployment. The total outflow is used because it is the only historic information available on a consistent basis for all years. The definition of the treatment and control groups follows the same rules as the ones used to estimate the New Deal program effect. The treatment group are all those aged 19-24-years-old living in Pathfinder areas and are being compared with individuals of the same age group living in all other areas (Panel 1) or in matched areas (Panel 2), and with older groups in Pathfinder areas (Panel 3 for the 25-30-years-old and Panel 4 for the 31-40-years-old). The lighter lines represent $95 \%$ confidence bands.

also confirm the importance of the estimated impact of the New Deal by comparing participants with older groups.

\subsection{National Roll-Out: Men's Results}

Table 3 contains the main result from the National Roll-Out. The first row shows an implied effect of around $5 \%$ on a preprogram base outflow (Table 2) of $25.8 \%$, and once more, the method used does not seem the affect the result significantly. Although this is still a substantial impact, it is about half the magnitude estimated for the pilot period. These differences in size can be 


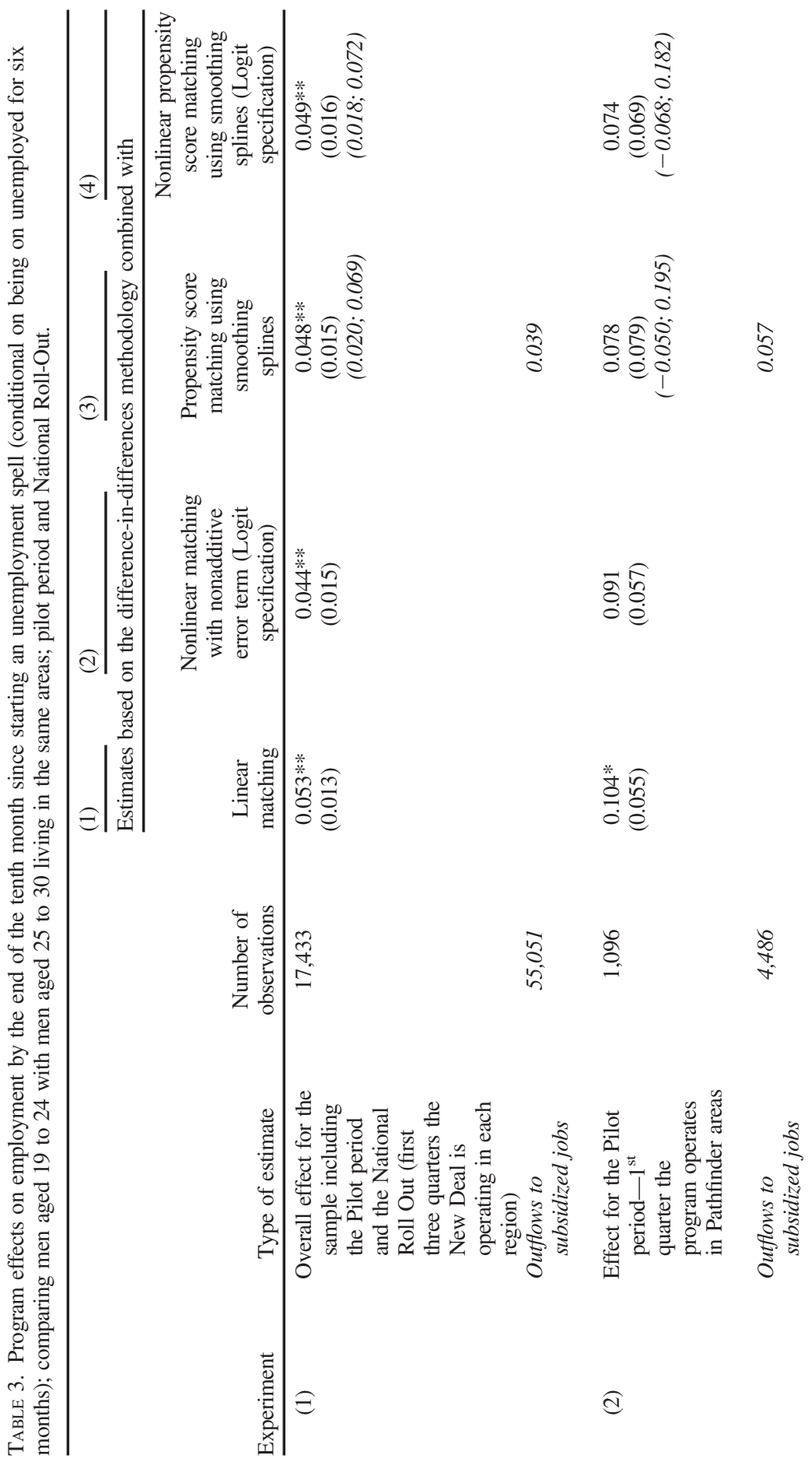




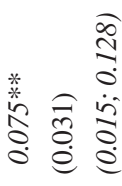

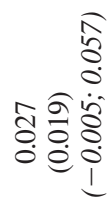

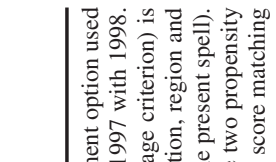

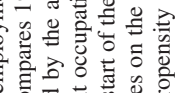

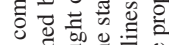

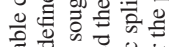

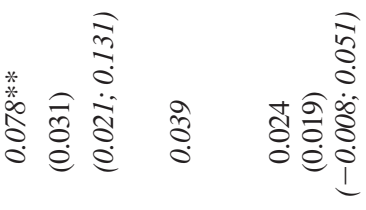

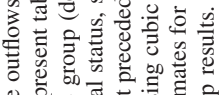

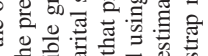

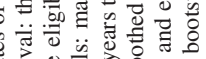

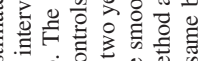

영 0 o

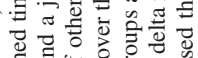

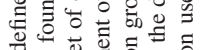

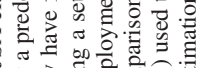

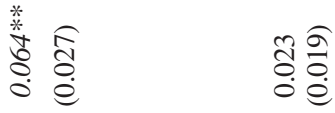

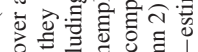

은 它. 焉

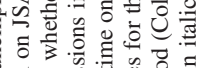

के

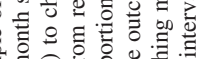

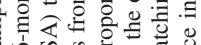

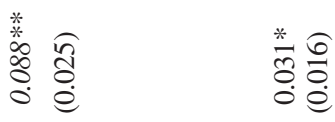

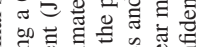

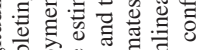

형응

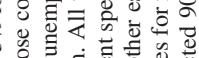

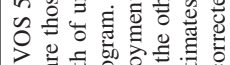

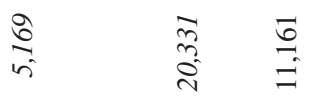

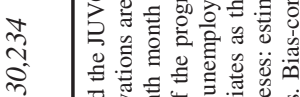

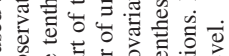

等

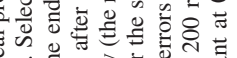

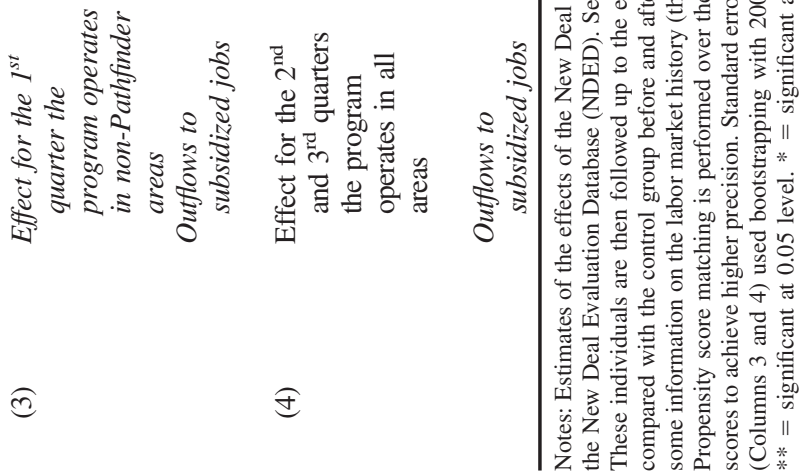


accounted for by a "program introduction" effect. In the first few months the program is operating, a very large increase in the flows to employment is observed, which then falls as the program matures. This is illustrated in the other rows of the table. The second and third rows report comparable estimates of the Gateway effect after four months of treatment for the first quarter the program operates in the Pathfinder and non-Pathfinder areas, respectively. As noted before, estimates for the pilot period (first quarter in Pathfinder areas) are about twice the size of the effect over the whole period. The same is also true if one considers the estimates for the first quarter the New Deal operates in nonPathfinder areas (see row 3). The fourth row presents estimates obtained using the following second and third quarters the program is operating and these are comparatively much lower and less significant.

There are, of course, many possible explanations for this. One explanation is that the agencies involved in delivering the program are initially very enthusiastic, but this enthusiasm naturally erodes over time. Another possibility is that the program diminishes welfare fraud. This would have particularly important effects during the first few months after the release of the program since potential participants are unlikely to be aware of the new claiming rules. Similar "cleaning up the register" effects have been noted of previous U.K. labor market reforms. ${ }^{28}$

There are many possible criticisms of the results. We shall now discuss some of the main ones-quality of job matches, selectivity, and differential trends. How the program affects the women will be discussed on the next subsection.

First, there is the issue of whether the quality of job matches has improved (or deteriorated) under the New Deal. One of the benefits from the New Deal is said to be that job matches are of higher quality due to greater job assistance and mentoring of the Personal Advisor. For those who get onto the employer option there is a guarantee of one-day-a-week training. On the other hand tougher monitoring may push claimants into low-quality matches. Quality is difficult to measure without data on earnings and other job characteristics. One indicator of job match quality, however, is simply the longevity of a job. Following the governments preferred measure, we define a "sustained" job as one that lasts at least 13 weeks. The first row of Table 4, Panel A repeats the analysis but uses the outflow to sustained jobs (instead of any job) as the outcome variable. The results are quite consistent with the earlier findings - the estimates point to an increase in the outflows to sustained jobs of $4.5 \%$ (in column 1 of Table 4), which compares to estimates of around 5\% for the outflows to all employment (in column 1, first row of Table 3).

Second, there is the issue of selectivity. It may be that the introduction of

28. See Van Reenen (2001) for discussion of Restart and the introduction of JSA. 
the New Deal has an effect on the (unobserved) quality of the inflow of individuals reaching six months of JSA. Having learned about the eligibility rules, potential participants may change their behavior in order to secure or avoid enrollment. The most likely route for this is that claimants in the fifth or sixth months of JSA may alter their behavior. If they believe the New Deal regime is "tougher" than the previous regime, they may be more likely to leave the unemployment rolls (this was one of the ways that RESTART, another job assistance program introduced in 1986 was deemed to have worked). On the other hand, if the New Deal is seen as a desirable thing (e.g., because of subsidies to "good jobs" or training), then claimants may delay exit. If the main effect is increased toughness, then we may underestimate the positive effects of the New Deal given a consequent decline of the unobserved quality of the stock (assuming the most job ready decide to leap into jobs before they are pushed off the unemployment rolls). If the New Deal is perceived as more attractive than the previous regime (as the qualitative evidence suggests) then we may actually be overestimating the effects of the Gateway period as the more job ready actually delay their exits prior to entering the Gateway.

To investigate these selectivity problems we examine outflows to employment during the fourth and fifth month of JSA, using the same methodology as before. The results are presented in rows 2 and 3 of Table 4, Panel B. The introduction of the New Deal had no significant impact on the outflows to employment prior to six-months' duration. All the estimates are small and insignificant at conventional levels.

Third, we have not controlled for differential trends. Using the historical distribution of year-by-year estimates of the impact of a fictitious program, we can construct an upper and lower bound to the estimated effect. This is done by taking the percentiles on the tail of the distribution-say, percentiles 5 and 95 or 10 and 90 - as being the expected value of the estimates in the absence of a program, and using them to rescale the estimated impact up or down accordingly. The average effect is again smaller than the estimates for the pilot period (see rows 5 and 6 of Table 4, Panel C). Nevertheless, even at the lower bound there is a significant effect of the program on the outflow rates to all destinations.

\subsection{The Impact of the Program on Women}

Finally, note that we have focused our results on male job outflow rates. Three quarters of all participants in the New Deal are men, but clearly the impact on women is also of great interest. The results for women are not as clear-cut as those for men. This is mainly because there is a systematic trend in the labor market behavior of older (25-30) compared to younger (19-24) women. The 


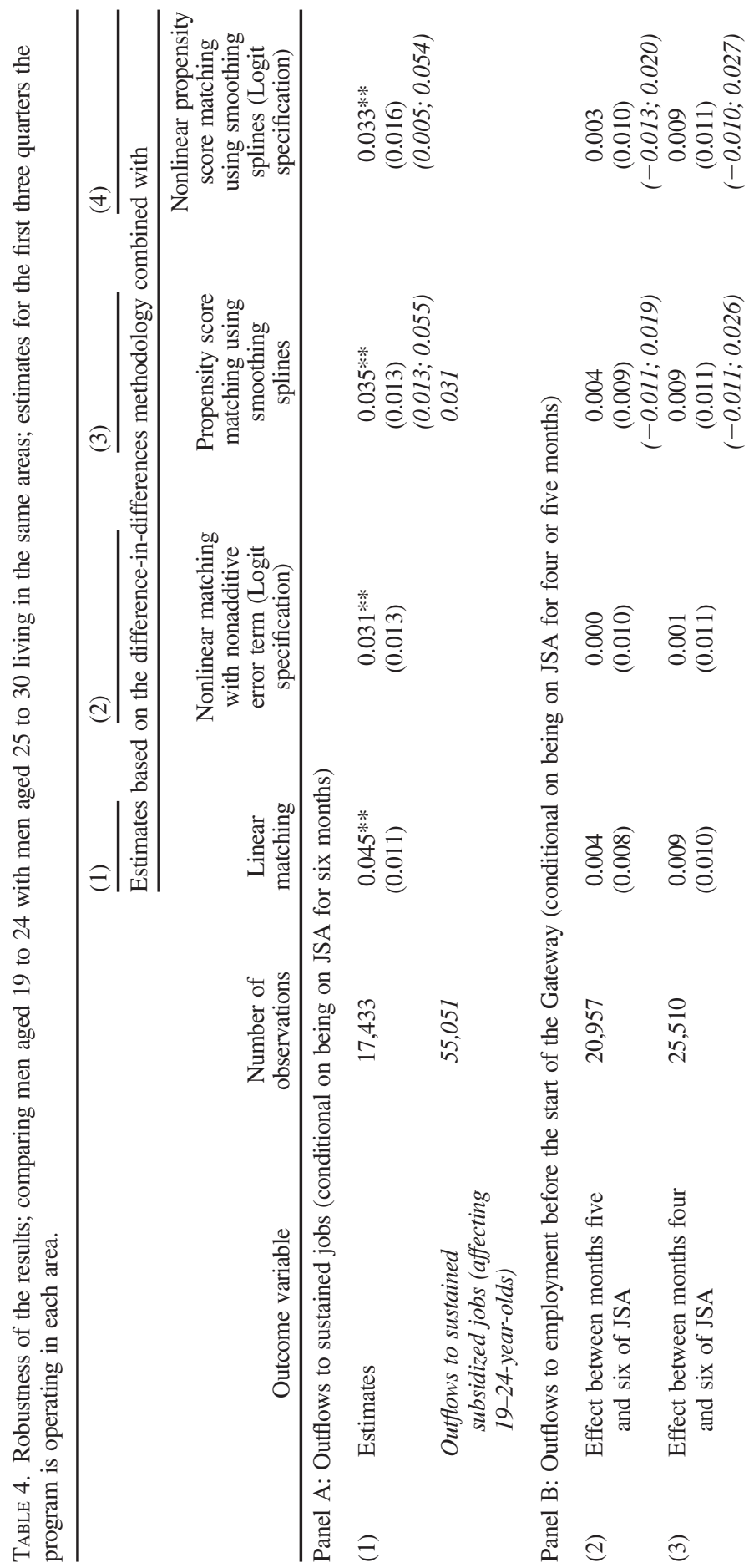



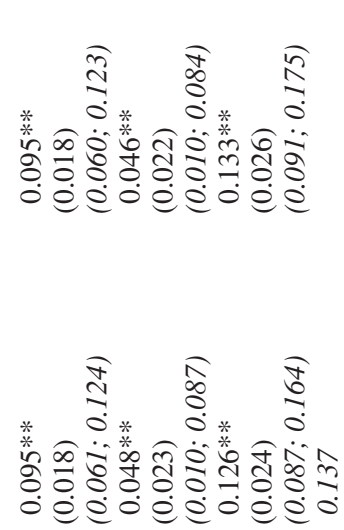

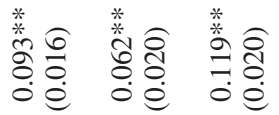

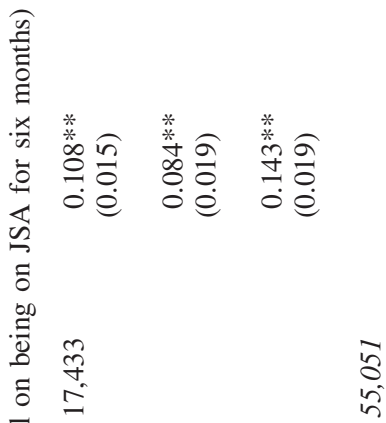

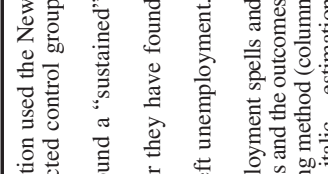

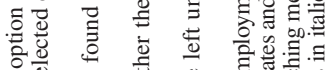

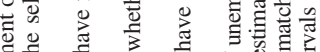

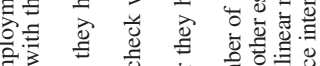

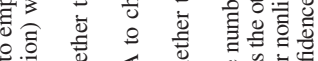

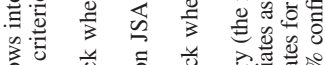

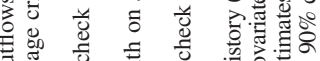

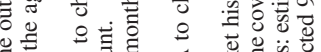

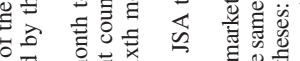

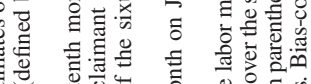

空

倇它

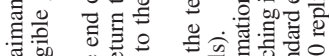

행

芯导

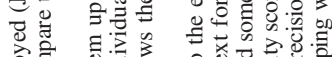

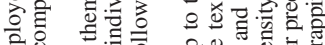

氙它

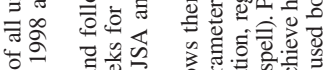

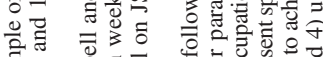

浣

के चे के

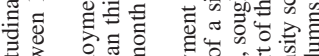

茄

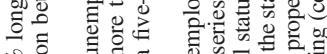

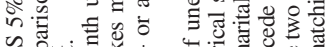

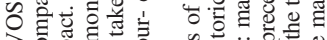

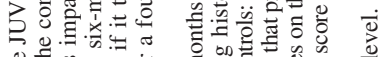

的可可

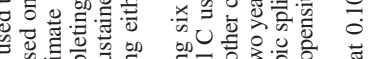

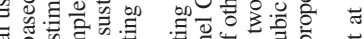

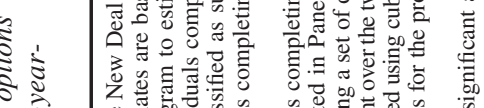

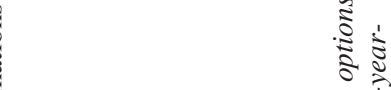

कृ

$\stackrel{i}{i}$

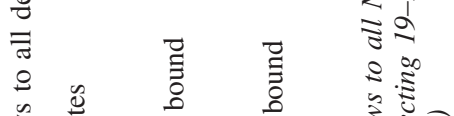

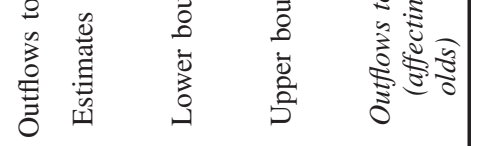

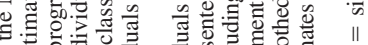

넝 0.0 .5 .

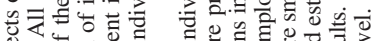

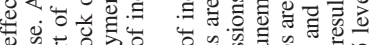

踏

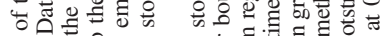

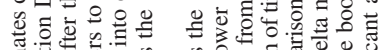

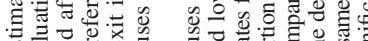

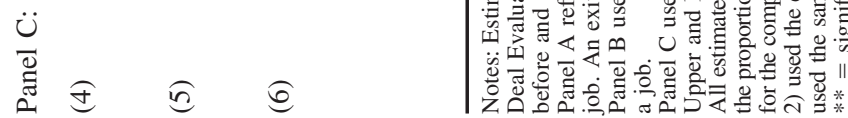



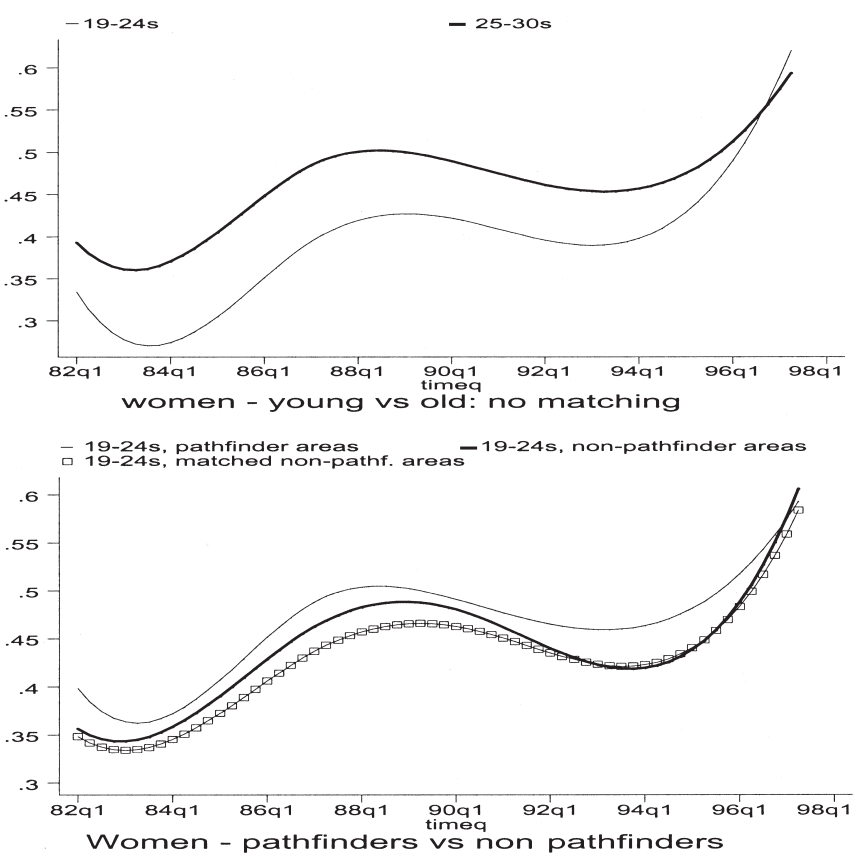

Figure 5. Outflows from JSA conditional on completing six months. Effect by the end of month 10. This graph illustrates the proportion of women leaving unemployment between the sixth and tenth months of unemployment 1982-1998. "PF" indicates that the men were living in a Pathfinder Pilot area (prior to New Deal introduction in 1998). The data have been smoothed by a cubic spline in time. Breakpoints were included at the first quarter of 1987 and the first quarter of 1990. No other covariates were included.

main problem, therefore, resides on the choice of the appropriate comparison group.

Figure 5 illustrates the difficulties encountered by plotting the conditional exits to all destinations against time for treatments and different possible comparison groups. It is apparent from the upper panel of Figure 5 that an estimator based on different age groups can be severely contaminated by differential trends. Compared to the younger age groups, the older age groups seem to have systematically improved their position in the labor market over the 1982-1999 period. If this trend extends to the treatment period, it is expected that such comparison underestimates the impact of treatment on the treated. On the other hand, the lower panel of the graph suggests that the macro shocks seem to affect younger age groups living in different geographic regions much more similarly, making the Pathfinder-non-Pathfinder 19-24-year-old groups comparable. Matching on regions improves the pattern, the two curves for treatment and comparisons being closer both in levels and slopes. The upshot of this is that 
using older women as a comparison group is not valid, and we should focus on the Pathfinder data to evaluate the effect of the New Deal for women.

Table 5 presents some estimates of the impact of the program on treated individuals using different comparison groups and estimation techniques. All estimates resulting from the comparison of similar age groups point to a positive effect of the program on the outflows to employment (see rows 1 and 2). These estimates are much less precise, more sensitive to the estimation technique used and generally smaller, but do not seem to reject the conclusions drawn for men. For example, the linear matching estimator in row 1 suggests an impact effect of $6.1 \%$ compared to $11.0 \%$ for men. The lack of precision is likely to be a consequence of the smaller sample sizes. Notice that the increased job taking-up rate seems to be mainly accounted for by the employment option, which ensured a job to almost $5 \%$ of the treated during this period. As expected, comparing different age groups changes the results drastically and in the predicted direction (see row 3): despite remaining statistically insignificant, the estimates are actually negative. Together with the pattern depicted in Figure 5, this explains why the women's case is not explored during the National Roll-Out of the program. The only group we can draw comparisons from is composed of individuals older than the participants, and these are subject to very differential trends.

\subsection{Discussion of the Results: A Comparison with the Existing Literature}

How do our findings compare with the existing results? We overlap with several other program evaluation literatures: Unemployment Insurance (UI) reform, wage subsidies, and youth measures over education and training. Perhaps the most directly relevant are the recent program evaluations of mandatory job search associated with welfare to work reforms. Bloom and Michalopoulos (2001) survey 29 different initiatives that had demonstration projects. Eight of these schemes were job-focused (rather than education/training-focused) and mandatory for welfare recipients. Table 6 summarizes the results from these studies and shows that although the precise impact effect differed, a positive impact was found in all eight cases. The median of the impacts in the final column of Table 6 is 0.23 , which is not wildly out of line with our "central" estimate of a program impact of 0.2 . Again we should note that 0.2 is probably an "upper-bound" measure since, as we have noted, a large part of this employment effect is towards subsidized jobs and also due to a "first-quarter" effect.

Unlike the U.S. welfare to work reforms where the affected groups are overwhelmingly females with children, the New Deal's main participants are men. Experiments over unemployment insurance reforms may, therefore, be more relevant. Meyer (1995) discusses five randomized trials and finds that increased job search assistance and monitoring significantly reduced the dura- 


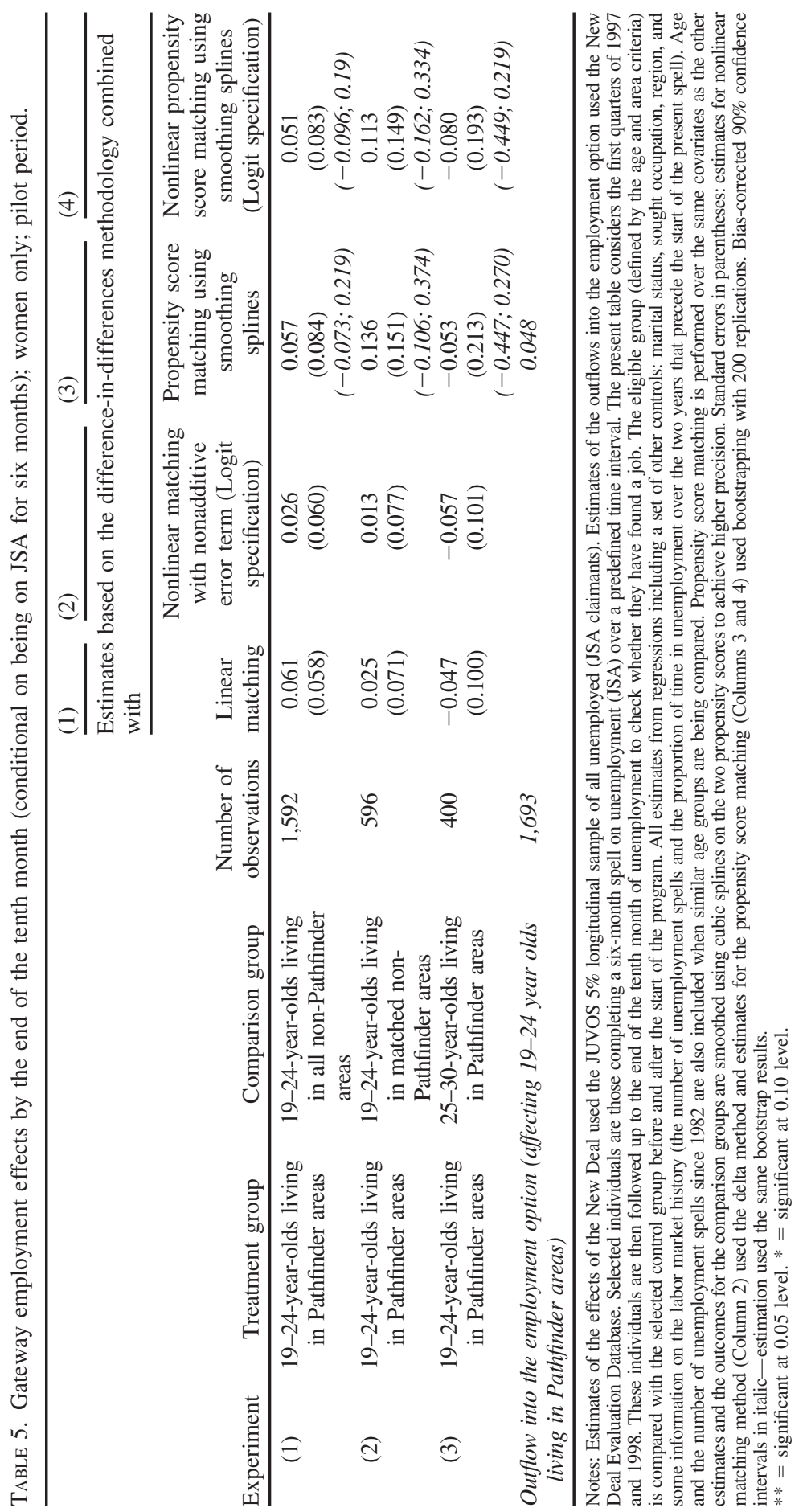


TABLE 6. Evaluations of the employment impact of welfare to work programs with mandatory employment services (random assignment); proportion who were ever employed in first year after treatment.

\begin{tabular}{|c|c|c|c|c|}
\hline Study & Sample size & $\begin{array}{l}\text { Control group } \\
\text { outcome } \\
\text { (\% employed) }\end{array}$ & $\begin{array}{l}\text { Impact of program } \\
\text { on treatment group } \\
\text { (additional \% } \\
\text { employed) }\end{array}$ & $\begin{array}{l}\text { Ratio of impact } \\
\text { effect to } \\
\text { control group } \\
\text { proportion } \\
\text { (= column } 4 \\
\text { divided by } \\
\text { column } 3 \text { ) }\end{array}$ \\
\hline \multicolumn{5}{|c|}{ Job-search first programs } \\
\hline $\begin{array}{l}\text { SWIM } \\
\text { Atlanta LFA } \\
\text { Grand Rapids LFA } \\
\text { Riverside LFA } \\
\text { LA Jobs First GAIN }\end{array}$ & $\begin{array}{r}2,850 \\
3,783 \\
3,010 \\
6,611 \\
15,122\end{array}$ & $\begin{array}{l}39 \% \\
48 \% \\
53 \% \\
35 \% \\
47 \%\end{array}$ & $\begin{array}{r}11 \% \\
5 \% \\
10 \% \\
17 \% \\
11 \%\end{array}$ & $\begin{array}{l}0.28 \\
0.1 \\
0.19 \\
0.48 \\
0.23\end{array}$ \\
\hline \multicolumn{5}{|c|}{ Employment-focused programs with mixed initial activities } \\
\hline $\begin{array}{l}\text { Project Independence } \\
\text { Riverside GAIN } \\
\text { Portland NEWWS }\end{array}$ & $\begin{array}{l}9,785 \\
4,640 \\
5,442\end{array}$ & $\begin{array}{l}50 \% \\
31 \% \\
47 \%\end{array}$ & $\begin{array}{r}4 \% \\
20 \% \\
11 \%\end{array}$ & $\begin{array}{l}0.08 \\
0.64 \\
0.23\end{array}$ \\
\hline
\end{tabular}

Source: Derived from Bloom and Michalopoulos (2001), Appendix Table C.1.

Notes: These are all of the employment-focused programs evaluated by MDRC using random assignment. Education and training focused programs (MDRC's definition) are not included. The "impact" column shows the difference in the proportion of the treatment group who got a job in the year after the program minus the same proportion in the control group. All impacts are statistically significant at the 0.05 level. The employment effect appears to diminish over time. With the exception of Portland, year three effects are all smaller than year one effect.

tion of unemployment claims (see also Katz and Meyer 1990, and Meyer 1990). As with the New Deal it is unclear from these studies whether the "carrot" of job assistance or the "stick" of the tougher monitoring of job search played the most important role. Ashenfelter, Ashmore, and Dechenes (1999) claim to find no increased benefit of stricter enforcement over job search in their examination of random trials, but Anderson (2000) and Abbring, van den Berg, and van Ours (1997) do find evidence that sanctions and strict monitoring have important effects. Distinguishing between the relative importance of carrot and stick is an important area of ongoing research, but what seems to be less in doubt is that the combination of the two can be effective. It is interesting to note that in the study of worker profiling and reemployment services that involves mandatory employment and training services, Black et al. (2003) find most of the impact to be a sharp increase in early exits from UI associated with claimants finding out about their mandatory program obligations.

A feature of the New Deal is that it is youth-focused. Most evaluations of youth initiatives have been pessimistic, especially for young men (for example, Heckman, LaLonde, and Smith 1999). Our study gives some room for optimism, but it should be remembered that the participant group for most U.S. youth training programs are quite different from the British New Dealers. U.S. 
schemes are focused on very disadvantaged youth-for example, long-term unemployment is rare in the United States, but more common in Europe. It may be easier to help the young in the New Deal because they are far more "job-ready" than their U.S. counterparts. In addition (unlike JTPA) we are not looking at the impact of the training/education aspects of the New Deal and have focused only on the mandatory job search and wage subsidy element.

Finally, there is an extensive literature on the role of financial incentives for employers and individuals in encouraging employment among the less skilled. Employer-based job subsidies of the kind discussed here are rarer than individual-based incentives such as EITC. ${ }^{29}$ Both types of policy can be successful in raising employment, ${ }^{30}$ but this conclusion depends very much on the exact program. A major problem with employer-based wage subsidies is that they have very low take-up by employers, perhaps due to stigma or administrative burden. $^{31}$

In summary, the finding of a small positive employment effect of the New Deal is not out of line with the results in the U.S. literature. However, there remains the question of whether the social costs of the program justify the benefit. In this paper we do not embark on a full cost-benefit calculation since the longer-term effects of the program are unknown (especially the human capital raising elements). Nevertheless, Layard (2000) and Van Reenen (2001) make a preliminary attempt to gauge the costs using administrative data and assumptions over the size of earnings gains. They both find that the social benefits outweigh the social costs.

\section{Conclusions}

This paper has examined the labor market impact of the British New Deal for Young People. The New Deal is a compulsory program affecting all young people claiming unemployment benefit for at least six months. The program offers a combination of treatments, particularly job assistance for four months and a wage subsidy paid to employers. Two sources of identification are used to construct comparison groups in order to make inferences on the impact of the New Deal: a comparison between pilot areas and nonpilot areas and age-related eligibility criteria. Our results suggest similar quantitative effects whichever comparison group is chosen.

Based on the pilot period of the program we find an economically important and statistically significant effect of the program on outflows to employment

29. See Eissa and Leibman (1996) for an evaluation.

30. See Blank, Card, and Robins (2001) for example.

31. Katz (1998). See also Burtless (1985) and Dubin and Rivers (1993) for evaluations of wage subsidy programs. 
among men. The program appears to have caused an increase in the probability of young men (who had been unemployed for six months) finding a job in the next four months. On average, this increase is about 5 percentage points (relative to a preprogram baseline of about 26\%). Part of this overall effect is the job subsidy element and part is a pure enhanced job search. We estimate that at least 1 percentage point of the 5 percentage points is due to the Gateway services, such as job search assistance (rather than the wage subsidy element). We also found that the treatment impact is much larger in the first quarter of introduction compared to the subsequent two quarters (at least a 5-percentagepoint increase to unsubsidized jobs). This puts in question whether the effects of this aspect of the program will be sustained in the long run. Our findings are robust to a large number of experiments, including a number of different comparison groups.

Why are our nonexperimental program evaluation results more robust than those seen elsewhere in the literature? We suspect that it is due to the combination of having a clear "before-and-after" design and matching our treatment group closely with a comparison group of similar duration on unemployment insurance. It is worthwhile recalling that both LaLonde (1986) and Fraker and Maynard (1987) found when using comparison groups based on benefit receipt (AFDC) experimental and nonexperimental estimators gave much closer results than the "youth" group as a whole. Our results have a similar flavor.

There are at least three areas of further work. First, the main omission in our work is that we do not consider the longer-term effects of the New Deal. A full evaluation needs to consider whether individuals' employability has been enhanced by their experience of subsidized work and education and training. The data is only just becoming available to perform such an analysis. A second problem lies in untangling how robust our estimates are in the face of substitution and equilibrium wage changes. To take these into account involves putting more economic structure on the problem than we have done in this paper (e.g., Blundell, Costa Dias, and Meghir 2003). It is reassuring, however, that the Pathfinder pilots vs. nonpilot comparisons yielded results that were quantitatively similar to the within Pathfinder analysis. Finally, we have eschewed a formal cost-benefit analysis given the uncertainty surrounding some of the benefits such as the training and education option. However, this is clearly an important next step that will be informed by some of the estimates obtained in this paper.

\section{References}

Abbring, Jaap, Gerard van den Berg, and Jan van Ours (1997). "The Effect of Unemployment Insurance Sanctions on the Transition Rate from Unemployment to Employment." Tinbergen Institute Working Paper. 
Anderton, Bob, Rebecca Riley, and Garry Young (1999). The New Deal for Young People: Early Findings from the Pathfinder Areas. Employment Service Research and Development Employment Service Research, No. 34.

Anderson, Patricia (2000). "Monitoring and Assisting Active Job Search." Mimeo, Dartmouth College.

Ashenfelter, Orley and David Card (1985). "Using the Longitudinal Structure of Earnings to Estimate the Effect of Training Programs." Review of Economics and Statistics, 67, $648-660$.

Ashenfelter, Orley, David Ashmore, and Olivier Dechenes (1999). "Do Unemployment Insurance Recipients Actively Seek Work? Randomized Trials in Four U.S. States." National Bureau of Economic Research Working Paper No. 6982.

Bassi, Laurie (1984). "Estimating the Effects of Training Programs with Nonrandom Selection." Review of Economics and Statistics, 66(1), 36-43.

Bell, Brian, Richard Blundell, and John Van Reenen (1999). "Getting the Unemployed Back to Work: An Evaluation of the New Deal Proposals." International Tax and Public Finance, 6, 339-360.

Blank, Rebecca, David Card, and Philip Robbins (2000). "Financial Incentives for Increasing Work and Income Among Low Income Families." In Finding Jobs, edited by David Card and Rebecca Blank. Russell Sage Foundation, New York.

Bloom, David and Charles Michalopoulos (2001). "How Welfare and Work Policies Affect Employment and Income: A Synthesis of Research." MDRC.

Blundell, Richard and Monica Costa Dias (2000). "Evaluation Methods for Non-Experimental Data." Fiscal Studies, 21(4), 427-468.

Blundell, Richard, Monica Costa Dias, and Costas Meghir (2003). "The Overall Impact of Wage Subsidies under Idiosyncratic Uncertainty.” Working paper, Institute for Fiscal Studies.

Blundell, Richard, Monica Costa Dias, Costas Meghir, and John Van Reenen (2003). "Evaluating the Employment Effects of a Mandatory Job Search Program." University College London Discussion Paper 03-05.

Blundell, Richard, Lorraine Dearden, Alissa Goodman, and Howard Reed (1997). Higher Education, Employment and Earnings in Britain. Institute for Fiscal Studies Monograph Series.

Blundell, Richard, Alan Duncan, and Costas Meghir (1998). "Estimating Labor Supply Responses using Tax Policy Reforms." Econometrica, 66, 827-861.

Burtless, Gary (1985). "Are Targeted Wage Subsidies Harmful? Evidence from a Wage Voucher Experiment." Industrial and Labor Relations Review, 39, 105-114.

Card, David and Dean Hyslop (2002). "Estimating the Dynamic Effects of an Earnings Subsidy for Welfare Leavers." Working paper, University of California, Berkeley.

Davidson, Charles and Stephen Woodbury (1993). "The Displacement Effects of Reemployment Bonus Programs." Journal of Labor Economics, 11(4), 575-605.

Dearden, Lorraine, Carl Emmerson, Chris Frayne, Alissa Goodman, Hide Ichimura, and Costas Meghir (2001). "Evaluating the Education Maintenance Allowance in the U.K." Working paper, Institute for Fiscal Studies. Invited presentation, Royal Economic Society Conference 2001.

Deheijia, Rajeev and Sadek Wahba (1998). "Propensity Score Matching Methods for Nonexperimental Causal Studies.” Working paper no. 6829, National Bureau of Economic Research.

Dehejia, Rajeev and Sadek Wahba (1999). "Causal Effects in Non-experimental Studies: Reevaluating the Evaluation of Training Programs." Journal of the American Statistical Association, 94(448), 1053-1062.

Dickens, Richard, Steve Machin, and Alan Manning (1999). "The Effects of Minimum 
Wages on Employment: Theory and Evidence from Britain.” Journal of Labor Economics, 17, 1-22.

Dubin, Jim and Don Rivers (1993). "Experimental Estimates of the Impact of Wage Subsidies.” Journal of Econometrics, 56, 219-242.

Eissa, Nada and Jeff Leibman (1996). "Labor Supply Response to the Earned Income Tax Credit." Quarterly Journal of Economics, 111, 605-637.

Fraker, Tom and Richard Maynard (1987). "The Adequacy of Comparison Group Designs for Evaluations of Employment Related Programs." Journal of Human Resources, 22, $194-$ 227.

Hahn, Jin, Petra Todd, and Wilbert Van der Klaauw (1999). "Identification and Estimation of Treatment Effects with Regression Discontinuity Design.” Working paper, UNC.

Hales, Jon, Debbie Collins, Charles Hasluck, and Steve Woodland (2000). "New Deals for the Young People and Long Term Unemployed: Survey of Employers." Employment Service Report No. 58, National Center for Social Research.

Heckman, James J. (1979). "Sample Selection Bias as a Specification Error." Econometrica, 47, 153-161.

Heckman, James J. and Joe Hotz (1989). "Choosing Among Alternative Nonexperimental Estimators for Estimating the Impact of Social Programs." Journal of the American Statistical Association, 84, 862-874.

Heckman, James J., Hide Ichimura, and Petra Todd (1997). "Matching as an Econometric Evaluation Estimator: Evidence from Evaluating a Job Training Program." Review of Economic Studies, 64, 605-654.

Heckman, James J., Robert LaLonde, and Jeff Smith (1999). "The Economics and Econometrics of Active Labor Market Programs" In Handbook of Labor Economics, Volume 3, edited by Orley Ashenfelter and David Card. North Holland.

Heckman, James J., Lance Lochner, and Chris Taber (1998). "Rising Wage Inequality: Explorations with a Dynamic General Equilibrium Model of Earnings with Heterogeneous Agents." Review of Economic Dynamics, 1, 1-58.

Heckman, James J. and Richard Robb (1985). "Alternative Methods for Evaluating the Impact of Interventions." In Longitudinal Analysis of Labor Market Data. Wiley.

Heckman, James J. and Richard Robb (1986). "Alternative Methods for Solving the Problem of Selection Bias in Evaluating the Impact of Treatments on Outcomes." In Drawing Inferences from Self-Selected Samples, edited by Howard Wainer. Springer Verlag, Berlin.

Katz, Larry (1998). "Wage Subsidies for the Disadvantaged.” In Generating Jobs, edited by Richard Freeman and Peter Gottschalk. Russell Sage Foundation, New York.

Katz, Larry and Bruce Meyer (1990). "Unemployment Insurance, Recall Expectations and Unemployment Outcomes." Quarterly Journal of Economics, 105(4), 973-1002.

Knab, John, Jan Bos, David Friedlander, and Mike Weissman (2000). "Do Mandates Work? The Effects to Enter a Welfare to Work Program." Working paper, Manpower Development Research Corporation, New York.

LaLonde, Robert (1986). "Evaluating the Econometric Evaluations of Training Programs with Experimental Data." American Economic Review, 76, 604-620.

Layard, Richard (2000). "Welfare to Work and the New Deal." The Business Economist, 31(3), 28-40.

Levine, Philip B. (1993). "Spillover Effects Between the Insured and Uninsured Unemployed." Industrial and Labor Relations Review, 47(1), 73-86.

Meghir, Costas and Marten Palme (2003). "Ability, Parental Background and Education Policy: Empirical Evidence from a Social Experiment.” Working paper no. 03/05, Institute for Fiscal Studies.

Meyer, Bruce (1990). "Unemployment Insurance and Unemployment Spells." Econometrica, 58(4), 757-782. 
Meyer, Bruce (1995). "Lessons from U.S. Unemployment Insurance Experiments." Journal of Economic Literature, 33(1), 91-131.

Smith, Jeff and Petra Todd (2004). "Does Matching Overcome LaLonde's Critique of Nonexperimental Estimators?" Journal of Econometrics, forthcoming.

Van Reenen, John (2001). "Active Labor Market Policies and the British New Deal for Unemployed Youth in Context.” Institute for Fiscal Studies, Working Paper No. 01/09 Forthcoming In Seeking a Premier League Economy, edited by Richard Blundell, David Card, and Richard Freeman. University of Chicago Press.

Woodbury, Steve and Robert Spiegelman (1987). "Bonuses to Workers and Employers to Reduce Unemployment: Randomized Trials in Illinois." American Economic Review, 77, 513-530. 